\title{
Neighbourhood socioeconomic characteristics and blood pressure among Jamaican youth: a pooled analysis of data from observational studies
}

\author{
Trevor S Ferguson ${ }^{\text {Corresp., } 1}$, Novie OM Younger-Coleman ${ }^{1}$, Jasneth Mullings ${ }^{2}$, Damian Francis ${ }^{3}$, Lisa-Gaye Greene ${ }^{4}$, \\ Parris Lyew-Ayee ${ }^{4}$, Rainford Wilks ${ }^{1}$ \\ ${ }^{1}$ Epidemiology Research Unit, Caribbean Institute for Health Research, The University of the West Indies, Mona, Kingston, Jamaica \\ 2 Health Research Resource Unit, Dean's Office, Faculty of Medical Sciences, University of the West Indies, Mona, Kingston, Jamaica \\ 3 School of Health and Human Performance, Georgia College and State University, Milledgeville, GA, United States \\ 4 Mona Geolnformatics Institute, The University of the West Indies, Mona, Kingston, Jamaica \\ Corresponding Author: Trevor S Ferguson \\ Email address: trevor.ferguson02@uwimona.edu.jm
}

INTRODUCTION: Neighbourhood characteristics are associated with several diseases, but few studies have investigated the association between neighbourhood and health in Jamaica. We evaluated the relationship between neighbourhood socioeconomic status (SES) and blood pressure (BP) among youth, 15-24 years old, in Jamaica.

METHODS: A pooled analysis was conducted using data from three studies (two national surveys and a birth cohort), conducted between 2005-2008, with individual level BP, anthropometric and demographic data, and household SES. Data on neighbourhood SES were obtained from the Mona Geo-Informatics Institute. Neighbourhood was defined using community boundaries from the Social Development Commission in Jamaica. Community characteristics (poverty, unemployment, dependency ratio, population density, house size, and proportion with tertiary education) were combined into SES scores using principal component analysis (PCA). Multivariable analyses were computed using mixed effects multilevel models.

RESULTS: Analyses included 2556 participants (1446 females; 1110 males; mean age 17.9 years) from 306 communities. PCA yielded two neighbourhood SES variables; the first, PCA-SES1, loaded highly positive for tertiary education and larger house size (higher value = higher SES); while the second, PCASES2, loaded highly positive for unemployment and population density (higher value = lower SES). Among males, PCA-SES1 was inversely associated with systolic BP $(\beta-1.48[95 \% \mathrm{Cl}-2.11,-0.84] \mathrm{mmHg}, \mathrm{p}$ $<0.001$ for each standard deviation unit increase in PCA-SES1 score) in multivariable model accounting for age, household SES, study, BMI, fasting glucose, physical activity and diet. PCA-SES1 was not significantly associated with systolic BP among females $(\beta-0.48[-1.62,0.66], p=0.410)$ in a similar model. Associations for PCA-SES2 was assessed using linear splines to account for non-linear effects. The were no significant associations between systolic BP and PCA-SES2 among males. Among females, higher PCA-SES2 (i.e. lower SES) was associated with higher systolic BP at spline 2 [z-score -1 to 0 ] ( $\beta 4.09$ $[1.49,6.69], p=0.002)$, but with lower systolic BP at spline 3 [z-core 0 to 1 ] ( $\beta-2.81[-5.04,-0.59], p=$ 0.013). There were no significant associations between diastolic BP and PCA-SES1, but PCA-SES2 showed non-linear associations with diastolic BP particularly among males.

CONCLUSION: Higher neighbourhood SES was inversely associated with systolic BP among male Jamaican youth; there were non-linear associations between neighbourhood SES and systolic BP among

Peer) reviewing PDF | (2019:10:42392:2:0:NEW 8 Aug 2020) 
females and for diastolic BP for both males and females. 
1 NEIGHBOURHOOD SOCIOECONOMIC CHARACTERISTICS AND BLOOD

2 PRESSURE AMONG JAMAICAN YOUTH: A POOLED ANALYSIS OF DATA FROM

3 OBSERVATIONAL STUDIES

4

5 AUTHORS:

6 Trevor S Ferguson ${ }^{1}$, Novie OM Younger-Coleman ${ }^{1}$, Jasneth Mullings ${ }^{2}$, Damian Francis ${ }^{3}$, Lisa-

7 Gaye Greene ${ }^{4}$, Parris Lyew-Ayee ${ }^{4}$, Rainford Wilks ${ }^{1}$

8 INSTITUTIONS:

9 1. Epidemiology Research Unit, Caribbean Institute for Health Research, The University of the 10 West Indies, Mona, Kingston 7, Jamaica

11 2. Health Research Resource Unit, Dean's Office, Faculty of Medical Sciences, University of 12 the West Indies, Mona, Kingston 7, Jamaica

13 3. School of Health and Human Performance, Georgia College and State University, 14 Milledgeville, GA, USA

4. Mona GeoInformatics Institute, The University of the West Indies, Mona, Kingston 7, Jamaica

CORRESPONDING AUTHOR

Dr Trevor Ferguson

Epidemiology Research Unit, Caribbean Institute for Health Research,

21 The University of the West Indies, Mona, Kingston 7, Jamaica

22 Email: trevor.ferguson02@uwimona.edu.jm 


\section{ABSTRACT}

INTRODUCTION: Neighbourhood characteristics are associated with several diseases, but few studies have investigated the association between neighbourhood and health in Jamaica. We evaluated the relationship between neighbourhood socioeconomic status (SES) and blood pressure (BP) among youth, 15-24 years old, in Jamaica.

METHODS: A pooled analysis was conducted using data from three studies (two national surveys and a birth cohort), conducted between 2005-2008, with individual level BP, anthropometric and demographic data, and household SES. Data on neighbourhood SES were obtained from the Mona Geo-Informatics Institute. Neighbourhood was defined using community boundaries from the Social Development Commission in Jamaica. Community characteristics (poverty, unemployment, dependency ratio, population density, house size, and proportion with tertiary education) were combined into SES scores using principal component analysis (PCA). Multivariable analyses were computed using mixed effects multilevel models.

RESULTS: Analyses included 2556 participants (1446 females; 1110 males; mean age 17.9 years) from 306 communities. PCA yielded two neighbourhood SES variables; the first, PCASES1, loaded highly positive for tertiary education and larger house size (higher value $=$ higher SES); while the second, PCA-SES2, loaded highly positive for unemployment and population density (higher value = lower SES). Among males, PCA-SES1 was inversely associated with systolic BP ( $\beta-1.48$ [95\%CI -2.11, -0.84] mmHg, $\mathrm{p}<0.001$ for each standard deviation unit increase in PCA-SES1 score) in multivariable model accounting for age, household SES, study, BMI, fasting glucose, physical activity and diet. PCA-SES1 was not significantly associated with systolic BP among females $(\beta-0.48[-1.62,0.66], \mathrm{p}=0.410)$ in a similar model. Associations for PCA-SES2 was assessed using linear splines to account for non-linear effects. The were no significant associations between systolic BP and PCA-SES2 among males. Among females, higher PCA-SES2 (i.e. lower SES) was associated with higher systolic BP at spline 2 [z-score -1 to 0 ] $(\beta 4.09$ [1.49, 6.69], $\mathrm{p}=0.002)$, but with lower systolic BP at spline 3 [z-core 0 to 1$]$ ( $\beta$ $-2.81[-5.04,-0.59], \mathrm{p}=0.013)$. There were no significant associations between diastolic BP and PCA-SES1, but PCA-SES2 showed non-linear associations with diastolic BP particularly among males. 
52 CONCLUSION: Higher neighbourhood SES was inversely associated with systolic BP among

53 male Jamaican youth; there were non-linear associations between neighbourhood SES and 54 systolic BP among females and for diastolic BP for both males and females.

55

56

57 


\section{INTRODUCTION}

Neighbourhood characteristics, in particular conditions of the physical and social environment, have been shown to be associated with a number of health-related conditions (Arcaya et al. 2016; Diez Roux 2016; Diez Roux \& Mair 2010; Duncan \& Kawachi 2018; Oakes et al. 2015; Pemberton \& Humphris 2016; Ribeiro 2018). Research in this area has grown exponentially in the last twenty years, with obesity and depression being among the conditions most often studied (Arcaya et al. 2016; Diez Roux 2016; Diez Roux \& Mair 2010; Oakes et al. 2015). Other outcomes studied include cardiovascular health, allostatic load, diabetes, dietary practices, physical activity, alcohol consumption and tobacco use (Airaksinen et al. 2015; Assari et al. 2016; Diez Roux 2016; Ribeiro et al. 2019; Unger et al. 2014). Neighbourhood characteristics assessed include poverty, deprivation, walkability, food environment, healthy food availability, fast food density, air pollution, traffic noises, social cohesion, crime, victimization, fear of neighbourhood violence, and levels of urbanization, among others (Airaksinen et al. 2015; Arcaya et al. 2016; Assari et al. 2016; Diez Roux \& Mair 2010; Jivraj et al. 2019; Ribeiro et al. 2019; Unger et al. 2014). In general, these research studies have found that poorer neighbourhood conditions are associated with worse health outcomes (Diez Roux 2016).

Underlying mechanisms possibly include interactions between adverse environmental exposures, reduced sense of safety due to potential exposure to crime and violence, increase levels of adverse health behaviours and increased psychosocial stress (Diez Roux \& Mair 2010). The effects of neighbourhood on health can be conceptualized as being either compositional or contextual (Macintyre \& Ellaway 2003). The compositional effects refer to the differences in the characteristics of the people living in the neighbourhood, while the contextual effects are due to differences between the places (Macintyre \& Ellaway 2003). Contextual effects include collective social functioning and social practices (Macintyre et al. 2002). Overall, McIntyre and colleagues have proposed that features of the local area that influence health include: physical features of the environment, availability of healthy environments, services provided to support people in their daily lives, sociocultural features of the neighbourhood and the reputation of the area (Macintyre et al. 2002).

With regards to blood pressure, associations have been reported for systolic blood pressure, diastolic blood pressure and hypertension (Coulon et al. 2016; Fan et al. 2015; Liu et al. 2013), 
using indicators such as community level income, poverty, social and environmental characteristics and 'perceived neighbourhood crime and satisfaction'. Additionally, associations have been reported between attenuation of the normal nocturnal decrease in blood pressure (dipping) and higher levels of perceived neighbourhood problems (Euteneuer et al. 2014). Studies have also shown associations between neighbourhood characteristic and blood pressure in youth (McGrath et al. 2006). Possible mechanisms contributing to the effects of neighbourhood on blood pressures include poor dietary behaviour, increased obesity, higher consumption of alcohol and increased psychosocial stress (Chaix et al. 2010; Chaix et al. 2008; Euteneuer et al. 2014; Mujahid et al. 2011).

In Jamaica, research on the association between neighbourhood and health is limited. Cunningham-Myrie and colleagues found associations between characteristics of the neighbourhood environment and physical activity and obesity, with significant differences by sex (Cunningham-Myrie et al. 2015), while Mullings and colleagues found neighbourhood associations with depressive symptoms, again with significant sex differences (Mullings et al. 2013). Two other studies were identified, one reporting an association between neighbourhood crime and childhood malnutrition (Thompson et al. 2017) and the other reporting associations between perceived neighbourhood characteristics and depressive symptoms among adolescents in Jamaica and other Caribbean islands (Lowe et al. 2014). More recently associations have been reported between neighbourhood disorder and cumulative biological risk and substance use (Cunningham-Myrie et al. 2018; Felker-Kantor et al. 2019).

To our knowledge, no previous study on the relationship between blood pressure and neighbourhood characteristics has been conducted in Jamaica. Research on the neighbourhood effects on blood pressure is also limited in developing countries, among black populations and among youth. Studies have shown that social determinants of health often vary between countries and in different social context (Leng et al. 2015; Mackenbach et al. 2008), suggesting that findings are often not generalizable across countries or regions. Given the high burden or hypertension in developing countries and black populations (Gakidou et al. 2017; NCD Risk Factor Collaboration (NCD-RisC) 2017), and the fact that blood pressure tracks across the life course from childhood into adulthood (Chen \& Wang 2008), studies on the neighbourhood effects of blood pressure in these settings and among youth will further enhance our 
118 understanding and inform public health decisions. In light of the foregoing, this study forms part

119 of a larger body of work, exploring social and biological determinants of blood pressure in

120 adolescents and young adults in a predominantly black population from a developing country

121 (Ferguson et al. 2015; Ferguson et al. 2018). Previous studies evaluated individual and household

122 socioeconomic status but did not address the neighbourhood context.

123 This study therefore aimed to:

124

125

126

127

128

129

130

131

132

133

134

135

136

137

138

139

140

141

142

143

144

1. Evaluate the relationship between neighbourhood characteristics and systolic and diastolic blood pressure among Jamaican youth, 15-24 years old.

2. Evaluate whether the presence of elevated blood pressure or hypertension (BP $\geq 120 / 80$ $\mathrm{mmHg}$ ) is associated with neighbourhood characteristics.

Estimates will adjust for potential confounders including age, sex and household socioeconomic status and will also evaluate the effect of possible intermediary variables and independent covariates. We hypothesized that lower neighbourhood SES will be associated with higher systolic and diastolic blood pressure and higher prevalence of elevated blood pressure or hypertension. We chose to assess elevated blood pressure or hypertension as our high-risk category since the study involved adolescents and young adults and prevalence of hypertension would be relatively low in this age-group.

\section{METHODS}

\section{Data sources}

The study was conducted using data from three studies (two cross-sectional surveys and one birth cohort) which included measurements of blood pressure for youth aged $15-24$ years. We obtained data on neighbourhood characteristics from the Mona Geo-Informatics Institute Geographic Information Systems (GIS) Database. The studies included are 1) the 1986 Jamaica Birth Cohort Study 18-20 Follow Up (1986-JBCS), 2) The Jamaica Youth Risk and Resiliency Behaviour Survey 2006 (JYRRBS) and 3) The Jamaica Health and Lifestyle Survey 2007-2008 (JHLS-II). All studies were conducted by the Epidemiology Research Unit with one of the 
145 investigations (RJW) as the principal investigator for each study. All three studies were

146 previously approved by the University of the West Indies Ethics Committee (ethics approval 147 numbers: 1987 JBCS - no number, letter dated June 1, 2005, JYRRBS - ECP 71, 2005/2006, 148 JHLS-II - ECP 161, 2006/2007). Additionally, the proposal for this pooled analysis was 149 reviewed and approved by The University of the West Indies Ethics Committee (study number: 150 ECP 173, 16/17), prior to obtaining data on neighbourhood characteristics from the Mona Geo151 Informatics Institute. Participants provided written informed consent at the time of data 152 collection for the primary studies.

153 Details on the methods used in these studies have been previously published (Ferguson et al. 154 2010a; McCaw-Binns et al. 2011; Wilks et al. 2007; Wilks et al. 2008). We therefore present 155 only a brief description of each study and the Mona Geo-Informatics Institute.

156 The 1986-JBCS third follow up (Ferguson et al. 2010a; McCaw-Binns et al. 2011) was 157 conducted between 2005 and 2007 and included 902 young adults who were between 18-20 158 years old at the time of evaluation. Response rate was 74\% among contacted participants and $15955 \%$ of targeted participants (Ferguson et al. 2010a). Participants were part of a longitudinal 160 study of children born in Jamaica during the months of September and October of 1986 and were 161 originally part of the Jamaica Perinatal Mortality Survey. Measurements included blood 162 163 pressure, anthropometry, individual and household socioeconomic status as well a variety of laboratory markers of chronic disease.

164 165 166

JYRRBS (Wilks et al. 2007) was a national cross-sectional study, conducted in 2006, and included 1317 participants 15-19 years old. Response rate for this study was 99\% (McFarlane et al. 2014). The study evaluated lifestyle and behaviour risk factors for chronic noncommunicable disease, including mental health, reproductive and sexual health behaviours and factors which conferred resilience against adverse health behaviours.

JHLS-II (Wilks et al. 2008) was also a national health examination survey, conducted between 2007 and 2008 and included 2848 participants 15-74 years old. Response rate for this study was approximately $98 \%$ (Ferguson et al. 2017). The study collected data on chronic disease risk factors, health behaviours and socioeconomic status. JHLS-II included 520 persons who were 15-24 years old, who were therefore eligible for inclusion in this study. 
174 The Mona Geo-Informatics Institute (MGI) is an Institute of The University of the West Indies,

175 Mona, and provides several GIS resources to the University and other stakeholders. MGI has an

176 extensive human and social mapping database which includes geo-spatial data on environmental

177 characteristics, infrastructure and social characteristics, at the parish, constituency, electoral

178 division or community level. Data are derived from population censuses, government databases,

179 non-governmental organizations, private sector partners and international organizations. These

180 data are linked geo-spatially to MGI's extensive mapping of the island. Additional information is

181 available on the MGI website (http://www2.monagis.com/). For this study, MGI provided

182 community data for anonymized participants from the three studies. We provided MGI with each

183 participant's address or electoral district, which were used to map them in communities as

184 defined by The Planning Institute of Jamaica and the Social Development Commission (Planning

185 Institute of Jamaica 2006). Data on community characteristics were then merged with data from

186 each study. Each participant therefore had associated community level data which were used for

187 analyses.

188

189

190

191

192

193

194

195

196

197

198

199

200

201

202

203

\section{Measurements}

The study used previously collected data from the studies described above and from MGI databases. Data collection for all the included studies followed similar standardized protocols. In all studies, blood pressure was measured using a mercury sphygmomanometer (W.A. Baum \& Co; New York) after the participant had been seated for five minutes. The mean of the second and third systolic and diastolic blood pressures were used for the analysis. Elevated blood pressure or hypertension was defined as systolic blood pressure $\geq 120 \mathrm{mmHg}$ or diastolic blood pressure of $\geq 80 \mathrm{mmHg}$ or being on medication for hypertension. This categorization includes persons classified as prehypertension or hypertension in The Seventh Report of the Joint National Committee on Prevention, Detection, Evaluation, and Treatment of High Blood Pressure and as elevated blood pressure or hypertension in the 2017 American College of Cardiology / American Heart Association Guidelines (Chobanian et al. 2003; Whelton et al. 2018). This cut-point was used given that the prevalence of hypertension would be relatively low in the age-group included in the study, and the fact that studies have shown that blood pressure levels in the range $120-139 \mathrm{mmHg}$ systolic and $80-89 \mathrm{mmHg}$ diastolic are associated with higher cardiovascular risk (Ferguson et al. 2008; Lewington et al. 2002; Vasan et al. 2001). 
204 Weight was measured using a portable digital scale (Tanita brand, Tokyo, Japan) and height

205 measured with a portable stadiometer (Seca, Hamburg, Germany). Body mass index (BMI) was

206 calculated by dividing the weight (in kilograms) by the square of height (in meters). Study

207 specific internal BMI z-scores were obtained and used for bivariate and multivariable analyses.

208 Waist and hip circumferences were measured with a non-stretchable nylon tape measure. Data on

209 individual and household socioeconomic status were collected using interviewer administered

210 questionnaires. Household socioeconomic status was assessed using number of reported

211 household assets, categorized into thirds. Data on physical activity were obtained using a locally

212 developed questionnaires for the 1986-JBCS and JHLS-II and the International Physical Activity

213 Questionnaire short form (https://sites.google.com/site/theipaq/) for the JYRRBS. For each

214 study, participants were classified as having high, moderate or low physical activity levels.

215 Classification rules for the locally developed questionnaires have been previously published

216 (Ferguson et al. 2011; Ferguson et al. 2010a), while the classifications used in JYRRBS can be

217 found at the IPAQ support site (https://sites.google.com/site/theipaq/scoring-protocol). We did

218 not have data on salt intake and therefore frequency of fast food consumption was used as a

219 surrogate for high salt diet. Data on fast food consumption was collected by questionnaire and

220 categorized as less than twice per week, 2 to 4 times per week or five or more times per week.

221 As stated above, data for neighbourhood characteristics were collated by MGI from population

222 censuses, various governmental and non-governmental organizations, and private sector partners.

223 We opted to use these data to evaluate neighbourhood socioeconomic status because there were

224 no generally accepted measures for use in Jamaica. Previous studies have used indexes based on

225 aspects of the built environment, services, poverty, education and crime (Cunningham-Myrie et

226 al. 2015; Mullings et al. 2013), however some of these variables were only available for JHLS-II.

227 Details on the variables used in this paper and data sources are provided in Tables S1 in the

228 Supplemental Information S1 file. Derivation of the community socioeconomic status scores are

229 described below under statistical methods.

230 For these analyses, neighbourhood was defined as the community in which the participants lived.

231 In Jamaica, community boundaries are defined by the Social Development Commission

232 (website: https://sdc.gov.jm/) as geographic areas grouping people based on common ownership

233 of resources or sharing of social, economic or cultural facilities. The country is thus divided into 
234 parishes, developmental areas, communities and districts. Jamaica has 14 parishes. In its most

235 recent listing, the SDC social boundaries include 775 communities. For the communities

236 included in this study, population ranged from just over 100 to over 60,000 community

237 members. Further description of the community characteristics is shown in Table S2 in the

238 Supplemental Information S1 file.

239

240

241

242

243

244

245

246

247

248

249

250

251

252

253

254

255

256

257

258

259

260

261

262

\section{Sample size and power}

Given that the analyses were conducted using previously collected data, we performed sample size calculations to assess if the available data were adequate to answer the primary research objective, i.e. association between systolic blood pressure and community SES score. Calculations were based on the observed correlation between systolic blood pressure and the neighbourhood socioeconomic status score (described below) and were performed for males and females separately. Correlation coefficients were -0.15 for females and -0.14 for males. Using Stata's 'power onecorrelation' command, with $\alpha=0.05$ and power of $80 \%$, we estimated that the required sample size for a simple random sample for females was 340 and for males 421 . In order to account for clustering of observations by community as used in the analyses (see below) we applied a design effect using the formula design effect $=1+(M-1) \times I C C$, where $\mathrm{M}=$ number of observations per cluster and ICC = intraclass correlation coefficient (Lohr 1999). The average number of observations per community was obtained using Stata's xtsum command; the ICCs were obtained from sex-specific mixed effects multi-level models with systolic blood pressure as the outcome variable and neighbourhood socioeconomic status score as the explanatory variable; cluster variables were parish and community. For females, the $M=6$ and ICC $=0.134$. For males, $M=5$ and ICC $=0.087$. These calculations yielded a design effect of 1.67 for females and 1.35 for males, so that the required sample size for females of 569 and for males 568. The available sample in our pooled analyses included 1446 females and 1110 males and would have adequate power for our primary analyses. Details of the sample size calculations are available in the Supplemental Information S2 file.

\section{Statistical methods}

Analyses were performed using Stata 14.2 (StataCorp, College Station, Texas). Individual datasets were prepared for each study, and variables recoded to ensure that codes were the same 
263 for variables to be used for this analysis. The three datasets were then merged into a single 264 dataset with a variable to indicate the study from which each participant came. Descriptive

265

266

267

268

269

270

271

272

273

274

275

276

277

278

279

280

281

282

283

284

285

286

287

288

289

290

291

292

293 statistics were then obtained, initially stratified by study, and then stratified by study and sex. Summary statistics were also obtained for all participants stratified by blood pressure category. We also performed analyses to assess whether there was evidence for additive interaction by sex and by study in the relationship between systolic BP and neighbourhood SES and other covariates included in the models. For all analyses, a $p$-value $<0.05$ was considered statistically significant.

Principal Component Analysis (PCA) was used to derive composite socioeconomic status (SES) variables. We initially assessed the correlation between the available SES variables and used variables with significant correlations for consideration in the PCA. We then used the KaiserMeyer-Olkin (KMO) test for sampling adequacy and the Bartlett test of sphericity to select the variables for inclusion in final PCA model (Hair et al. 2006). We aimed to choose a combination of variables with $\mathrm{KMO}>0.5$ and Bartlett test for sphericity with $\mathrm{p}<0.05$ (thus rejecting the null hypothesis that variables are uncorrelated). Based on these criteria, a final list of six community variables were chosen for inclusion in the PCA model $(\mathrm{KMO}=0.774$; Bartlett's test for sphericity $\mathrm{p}<0.001)$. These variables were: percent poverty, percent unemployment, dependency ratio, population density, percent of houses with two or more bedrooms, and proportion with tertiary education. We believe that these six variables had good content validity, representing aspects of income, education, employment, crowding and wealth (size of house) which are all factors related to neighbourhood socioeconomic position. Horn's parallel analysis method was used to select components to be used in the analysis; components having an adjusted eigenvalue greater than 1.0 used in the analyses (Dinno 2009; Hayton et al. 2004). This method yielded two PCA components which were then used to predict SES scores for each community. A graph showing the observed and adjusted eigenvalues is shown in Figure S1 in the Supplemental Information S1 file. Factor loadings for each variable included in the PCA components are shown in Table S3 in the Supplemental Information S1 file. We assessed face validity by checking the component scores against perceived social status of the communities based on the investigators' understanding of social class in Jamaica. Analyses were conducted using these PCA derived community SES scores treated as standardized z-scores or categorized into SES thirds. We also evaluated whether the relationship between systolic BP and the PCA-SES 
294 variables showed evidence for non-linear effects, by adding a quadratic term to the model.

295 Where there was evidence for a non-linear effect, we used linear splines in the bivariate and 296 multivariable models. Linear splines are used to estimate the relationship between outcome and

297 exposure as a piecemeal linear function, with the exposure variable divided into linear segments 298 joined at selected points called knots (Harrell 2015; StataCorp. 2015a).

299 We used multilevel regression models to evaluate the association between community SES and 300 blood pressure. Analyses with systolic and diastolic blood pressure as outcomes were done using 301 mixed effect linear regression models with maximum likelihood (ML) estimation, while analyses 302 with elevated blood pressure as the outcome were done with mixed effects logistic regression 303 models. The multi-level model accounted for individuals nested within communities, and 304 305 306 307 communities nested within parishes. The overall multilevel model structure was therefore: level 1 - individual study participants; level 2 - communities in which participant lived; level 3 parish in which community was situated. We report fixed effects coefficients adjusted for clustering by parish and community.

308

309

310

311

312

313

314

315

316

317

318

319

320

321

322

323

Multiple imputation by chained equations was used to account for missing data. Analyses were restricted to participants who had available data on the outcome variables, systolic and diastolic blood pressure, but missing data for all other variables were imputed when necessary. Eight variables had between 1 and 144 missing values, with the majority of variables having 10 or fewer missing values. Overall, 200 participants (7.8\% of total) had at least one missing value. Table S4 in the Supplemental Information S1 file presents a listing of the number and percentage of missing values for variables with missing values included in the analyses. A comparison of mean values for characteristics among complete cases versus those with missing values revealed no statistically significant differences; however, there was a statistically significant difference in the proportion of persons within thirds of the second PCA SES variable $\left(\chi^{2}=8.68, p=0.013\right)$. Based on this we assessed the data to be missing at random (MAR) (White et al. 2011). Using multiple imputation would therefore reduce potential bias associated with the complete case analysis and improve the power of the study (Nguyen et al. 2017; White et al. 2011). A stacked multiple imputed dataset comprising the original data set and 20 datasets with imputed values was therefore created using Stata's mi suite of commands (StataCorp. 2015b). Given that we had less than $10 \%$ of data missing, we chose to do 20 imputations as recommended by Graham and 
324 colleagues (Graham et al. 2007). Multiple imputation by chained equations was performed using

325 Stata's mi impute chained command (StataCorp. 2015b). The imputation model included the

326 outcome variables (systolic and diastolic blood pressure), the exposure variables (PCA-SES

327 standardized scores), sex, and all variables for which imputation were performed (age, BMI,

328 height, fasting glucose, fasting cholesterol, household possession, fast food consumption, and

329 physical activity levels). The syntax for the imputation models is shown in the Supplemental

330 Information S2 file. The imputed dataset was used for bivariate and multivariable models using

331 Stata's mi estimate commands; these commands run estimates on each of the imputed datasets

332 and combine estimates using Rubin's rules (Marshall et al. 2009; StataCorp. 2015b). For model

333 building we extracted the first imputed data set and performed regular (non-imputed) regression

334 analyses (Wood et al. 2008).

335 For multivariable analyses, we developed sequential models based on our hypothesized

336 associations, in order to assess the effect of potential confounders, intermediary variables or

337 independent covariates. Age, sex and household socioeconomic status were treated as potential

338 confounders, while BMI, glucose, physical activity and diet were considered possible

339 intermediary variables or independent covariates. A directed acyclic graph illustrating the

340 hypothesized association is shown in Figure S2 in the Supplemental Information S1 file. Sex-

341 specific models were used as there was evidence for interaction by sex for some variables (see

342 details in results section and in Table S5 in the Supplemental Information S1 file). Model 1

343 included the outcome variable and exposure variables along with age and household SES as

344 potential confounders. We also included a variable for study in this model to account for

345 differences due to the specific study participants were from. For model 2, BMI was added to the

346 model, and for model 3 we added glucose, physical activity and fast food consumption. We

347 opted to keep all the hypothesized variables in the full model so as to avoid potential biases from

348 variable selection (Greenland \& Pearce 2015). Based on the number of participants and the

349 number of variables in the full model, we had more than the 10-15 observations per covariate

350 coefficient for linear models as recommended by (Babyak 2004). For binary models, we had

351 more than four subjects per confounder coefficient as recommended by Greenland, and more

352 than ten events per variable as recommended by Peduzzi (Greenland et al. 2016; Greenland \&

353 Pearce 2015; Peduzzi et al. 1996). Additionally, there was no evidence for multicollinearity for

354 the variables included. Final models were run using the 20 stacked multiple imputation datasets 
355 for reporting. We also reran the models using complete cases only to assess whether our results

356 were influenced by the imputation. Model assessment was done by checking whether there was

357 evidence for collinearity or heteroscedasticity and whether the distribution of standardized

358 residuals deviated from the normal distribution assumption. We also assessed whether

359 multivariate outliers had any meaningful impact on the models. Where there was evidence of

360 heteroscedasticity, we used robust standard errors (Hamilton 2013).

361

\section{RESULTS}

363 Final analyses included 2556 participants (1446 females; 1110 males) from 306 communities.

364 Mean age was 17.9 years (standard deviation 2.0). There was evidence for significant clustering

365 of both systolic BP and diastolic BP within communities, with intra-class correlation coefficients

366 of $10.7 \%(95 \%$ CI $6.8-16.6 \%)$ and $10.9 \%$ (95\%CI $7.0-16.6 \%)$, respectively.

367 PCA yielded two components with adjusted eigenvalues $>1.0$ and these were used to derive two neighbourhood SES variables. These two variables were standardized using Z-scores for analyses. The first component, PCA-SES1, had an adjusted eigenvalue of 3.21 and explained $54 \%$ of the variance; this component loaded highly positive for tertiary education and larger house size (higher value = higher SES). The second component, PCA-SES2, had an adjusted eigenvalue of 1.40 and explained $24 \%$ of the variance; this component loaded highly positive for unemployment and population density (higher value = lower SES). Figure S1 in the

374 Supplemental Information S1 file shows the plot for the observed and adjusted eigenvalues for

375 the principal components, while Table S3 in the Supplemental Information S1 file shows the eigenvectors (factor loadings) for the individual variables included in PCA-SES1 and PCASES2. The investigators assessed the PCA-SES components as having good face validity, in that communities with high scores for PCA-SES1 were those generally accepted as high SES in the local context and those with high scores on PCA-SES2 were those accepted as having lower SES.

Table 1 shows summary statistics for characteristics of all study participants combined and for each of the three studies included in the analysis. Mean age ranged from 16.5 to 19.8 years and was highest for JHLS-II. While there were statistically significant differences for participant 
384

385

386

387

388

389

390

391

392

393

394

395

396

397

398

399

400

401

402

403

404

405

406

407

408

409

410

411

412

413

characteristics between studies, most of these differences were small, except for waist circumference which showed an approximately six-point difference, with mean value of $77.1 \mathrm{~cm}$ in JHLS-II compared to 71.6 in JYRRBS. Mean z-score for PCA-SES 1 was highest in the 1986JBCS (0.37) and lowest in the JYRRBS (-0.12), suggesting that participants from the 1986-JBCS had higher overall SES. This was supported by the distribution of individual community SES characteristics as shown in Table S2 in the Supplemental Information S1 file. Participants in the 1986-JBCS came from communities with larger populations, greater population density, less poverty, and lower dependency ratio. Mean z-score for PCA-SES 2 was also highest in the 1986JBCS. Prevalence of elevated blood pressure or hypertension was $29 \%$ overall and ranged from $21 \%$ in the $1986-J B C$ to $37 \%$ in JHLS-II (see Table 1). There were also significant differences in the distribution of persons in BMI categories, thirds of household possessions, fast food consumption categories and physical activity levels. Additional data with summary statistics for participant characteristics, stratified by study and sex, are shown in Table S6 in the Supplemental Information $\mathrm{S} 1$ file. There were significant sex differences for most of the participant characteristics.

Table 2 shows the means or percentages for participant characteristics within blood pressure categories, defined as normal $(<120 / 80 \mathrm{mmHg})$ and elevated BP or hypertension $(\geq 120 / 80$ $\mathrm{mmHg}$ ). Participants with elevated BP or hypertension were taller and heavier and had higher mean BMI and waist circumference. For the categorical variables, elevated BP was significantly associated with sex, BMI category, and physical activity level.

As stated before, we assessed whether the relationship between systolic BP and the PCA-SES variables showed evidence for non-linear effects by adding a quadratic term to the model. This was non-significant for PCA-SES1, but significant for PCA-SES2 $(p<0.001)$; we therefore used linear splines in the bivariate and multivariable analyses for PCA-SES2. We also assessed for interaction by sex and study. Tests for sex interaction were significant for the relationship between systolic BP and some covariates (age, BMI, PCA-SES2 at spline 4, and fast food consumption category 3-4 times/week), therefore we present sex-specific analyses for bivariate and multivariable models. Details of the sex interaction effects are shown in Table S5 of the Supplemental Information S1 file. There was no evidence for interaction by study in the relationship between systolic BP and PCA-SES1. For PCA-SES2, there was some evidence for 
414 interaction at spline 1 and 4 for females and spline 3 for males (see Table S7 in the Supplemental

415 Information S1 file). Given these interactions with study, in addition to our sex-specific models

416 in our primary results, we show study-specific estimates in the Supplemental Information S1 file.

417 Bivariate analyses using mixed effects linear regression with systolic BP as the outcome are

418 shown in Table 3. PCA-SES1 showed a statistically significant inverse association with systolic

419 BP among both males and females. A one standard deviation unit increase in PCA-SES1 score

420 was associated with a $1.45 \mathrm{mmHg}$ lower systolic BP among males $(\mathrm{p}<0.001)$ and $1.30 \mathrm{mmHg}$

421 lower systolic BP among females $(\mathrm{p}=0.003)$. For PCA-SES2 we report results for linear splines,

422 given the evidence for a non-linear effect mentioned above. Among males, a significant

423 association was seen only for spline 2 (z-score -1 to 0 ) where a one standard deviation increase

424 in PCA-SES2 (lower SES) was associated with a $2.6 \mathrm{mmHg}$ higher systolic blood pressure.

425 Among females, significant associations were seen for spline 1 (z-score $<-1)$, spline 2 (z-score -

4261 to 0 ), and spline 4 (z-score $>1$ ). Coefficients were 2.7 for spline $1,-3.5$ for spline 2 and -0.5 at

427 spline 4. Age and BMI were directly associated with systolic BP among both males and females,

428 while fasting glucose showed significant direct association among females only. Household

429 possession categories was inversely associated with systolic BP for the middle third among

430 males and the upper third among females. There was an inverse association with fast food

431 consumption for the 3-4 times/week category compared to the to the $\leq 2$ times/week category for

432 females only. No association was seen for physical activity levels in these models.

433 Results for bivariate analyses for diastolic BP are shown in Table 4. There were no significant 434 associations between diastolic BP and PCA-SES1, however inverse associations were seen for 435 males at spline 1 and females at spline 3 for PCA-SES2. When elevated BP or hypertension was 436 used as the outcome variable in bivariate analyses (Table S8 in the Supplemental Information S1 437 tables file), only PCA-SES1 was significantly associated with elevated BP or hypertension, and 438 this was seen only among males in the upper third of PCA-SES1 scores (odds ratio 0.65, $439 \mathrm{p}=0.015)$.

440 Sequential multivariable analyses with systolic BP as the outcome are shown in Table 5. These 441 results were derived from sex-specific mixed effects linear regression models, with cluster 442 variables being community and parish. Model 1 includes adjustments for age, household SES 443 and study. BMI is added to model 2 and glucose, physical activity and diet added in model 3. 
444 Among males, PCA-SES1 remained inversely associated with systolic BP in all models. The 445 coefficient was slightly attenuated (i.e. less negative) when adjustments were made in model 1, 446 changing from $-1.45(\mathrm{p}<0.001)$ in the unadjusted model to $-1.31(\mathrm{p}<0.001)$ in model 1; however, 447 addition of BMI to the model resulted in the magnitude of the coefficient increasing (i.e.

448 becoming more negative) to $-1.49(\mathrm{p}<0.001)$. There was no appreciable change in the coefficient 449 when fasting glucose, physical activity and diet were added to the model. Among females, the 450 significant association seen in the bivariate analysis was attenuated and no longer significant 451 when age, household possessions and study were added in model 1. The coefficient reduced in 452 magnitude from $-1.30(\mathrm{p}=0.003)$ in the unadjusted model to $-0.46(\mathrm{p}=0.423)$ in model 1 . The 453 addition of BMI (model 2) and other covariates (model 3) resulted in only very small changes in 454 the coefficient. For PCA-SES2, the association seen at spline 2 in the unadjusted model among 455 males was no longer significant in any of the sequential models, but a significant positive

456 457 458 459 460 461

462 463 464 465 466 467 association was seen at spline $4(\beta=0.94, \mathrm{p}=0.042)$ in model 2 only. Among females, PCASES2 was directly associated with systolic BP at spline 2 (z-score -1 to 0 ) with little change across the models. At this level a one standard deviation increase in PCA-SES2 (lower SES) was associated with a $4.09 \mathrm{mmHg}$ increase in systolic BP in the fully adjusted model. At spline 3 (zscore $>0$ to 1$)$, higher PCA-SES2 score was associated with lower blood pressure $(\beta=-2.81$, $\mathrm{p}=0.013$ in model 3).

Table 6 shows the sequential multivariable models with diastolic blood pressure as the outcome. There were no significant associations seen for PCA-SES1 in any of the models for males or females. Among males, a significant inverse association was seen at spline 1 (z-score $<-1)(\beta=$ $-4.10, \mathrm{p}<0.001$ in the fully adjusted model). There was a significant direct association at spline 2 ( $\mathrm{z}$-score -1 to 0$)(\beta=2.85, \mathrm{p}=0.002)$. Among females, there was a significant positive association between diastolic BP and PCA-SES2 at spline $1(\beta=1.06, \mathrm{p}=0.023)$.

Table 7 shows the odds ratio for elevated blood pressure or hypertension derived from sexspecific multi-level logistic regression models adjusted for age category, household SES, study, BMI categories, glucose category, physical activity and fast food consumption. Among males, the odds ratio for elevated blood pressure or hypertension for persons living in communities in the upper third of PCA-SES1 was 0.67 ( $\mathrm{p}=0.051$ ), suggesting that higher SES may be associated with lower odds of hypertension or elevated blood pressure, but did not achieve statistical 
474 significance in this study. There were no significant associations among females for thirds of

475 PCA-SES1. Thirds of PCA-SES2 was not associated with elevated blood pressure in males or 476 females.

477 In order to assess whether our results could have been influenced by the multiple imputation, we 478 re-ran the full models (model 3) with complete cases only (i.e. no imputations) for systolic and 479 diastolic blood pressure. These models are shown in Tables S9 and S10 of the Supplemental 480 Information S1 file. The associations seen were generally very similar to that seen in the models 481 with multiple imputation but given the smaller numbers (1019 for males and 1362 for females) 482 estimates were often less precise. We also assessed whether the observed associations differed 483 according to study by re-running the full final model for each study separately. These results are 484 shown in Tables S11 and S12 of the Supplemental Information S1 file. While there were some 485 differences in association in the different studies, associations were generally similar in direction 486 to the findings in the pooled analysis, however there was some variation in the magnitude of the 487 estimates; additionally, estimates were again imprecise with wide confidence intervals and often 488 not statistically significant.

\section{DISCUSSION}

We have shown from these analyses that lower community SES is associated with higher systolic BP among youth in Jamaica, particularly among males. This association persisted after adjusting for possible confounding by age and household SES and after accounting for the effects of BMI, fasting glucose, physical activity and diet (fast food consumption). Among females, the association with the first PCA-SES component was no longer significant after adjusting for confounders. Associations for the second PCA-SES component demonstrated non-linear effects. Diastolic BP also showed some non-linear associations for the second PCA-SES variable. However, while lower community SES may also be associated with higher odds of elevated blood pressure or hypertension among males, this did not achieve statistical significance.

The findings from this study adds to the body of literature showing an important contribution of neighbourhood conditions to health and underscores the importance of including the neighbourhood context when evaluating the social determinants of health. It also highlights that 
503 the relationship between neighbourhood SES and blood pressure may be complex, with both

504 linear and non-linear effects, thus necessitating a nuanced approach to our interpretation of these 505 associations. A relationship between neighbourhood SES and blood pressure in adults is fairly 506 well established, with several studies showing that lower neighbourhood SES was associated 507 with higher BP (Coulon et al. 2016; Fan et al. 2015; Liu et al. 2013; Morenoff et al. 2007; Riva 508 et al. 2016; Sprung et al. 2019). Additionally, Cho and colleagues found that lower 509 neighbourhood SES was associated with increased all-cause mortality among persons with newly 510 diagnosed hypertension in Korea (Cho et al. 2016). The relationship between neighbourhood 511 SES and BP among adolescents and young adults is less clear with some studies showing an 512 inverse association and others no significant association. Murakami and colleagues found that 513 neighbourhood socioeconomic disadvantage was associated with higher blood pressure among 514 Japanese dietary students at age 18-22 years, with those in the highest quartile of neighbourhood 515 socioeconomic disadvantage having $3 \mathrm{mmHg}$ higher SBP (Murakami et al. 2010). In another 516 study, McGrath and colleagues found that neighbourhood income, measured as percent at or 517 below the poverty line, was significantly associated with ambulatory systolic BP among 14-year 518 old adolescents in Pittsburgh (McGrath et al. 2006). In that study, each 1\% increase in the 519 percentage of community members at or below the poverty line was associated a $0.29 \mathrm{mmHg}$ 520 increase in systolic BP. Hofelmann and colleagues, in a study conducted in Brazil among 521 persons 20-29 years old, found that area level income was inversely associated with both SBP 522 and hypertension; being in the upper third of community income was associated with $5.7 \mathrm{mmHg}$ 523 lower SBP (Hofelmann et al. 2012). Data from the Birth to Twenty Cohort in South Africa also 524 found significant associations with a number of neighbourhood SES indices in bivariate analyses 525 at age 16 years, however only one of these remained statistically significant in the fully adjusted 526 model (Griffiths et al. 2012). Kwok and colleagues found that relative household income, but not 527 neighbourhood income, was inversely associated with blood pressure in Chinese adolescents at 528 age 13 (Kwok et al. 2015); while Chen and Paterson found no significant association between 529 neighbourhood SES and blood pressure (Chen \& Paterson 2006). In the Hong Kong Growth 530 Study of children 6-19 years, Ip and colleagues reported a significant association between 531 maternal education and hypertension, but no significant association between community income 532 and hypertension (Ip et al. 2016). Community income was however significantly associated with 533 obesity. The study did not report associations with SBP or DBP as continuous variables; such 
534 analyses may have been more likely to show an association given the higher statistical power

535 associated with continuous variable (Altman \& Royston 2006).

536 In this study, the association between neighbourhood SES and diastolic was seen only for the 537 second PCA-SES variable and showed non-linear effects. We have previously reported weaker 538 associations between diastolic BP and socioeconomic variables in a longitudinal analysis from 539 the 1986 Birth Cohort (Ferguson et al. 2015). Additionally, McGrath and colleagues found that 540 while neighbourhood SES was associated with systolic BP among adolescents in Pittsburgh, 541 there was no significant association with diastolic BP (McGrath et al. 2006). On the other hand, 542 Riva and colleagues in a study from Greenland found that while neighbourhood SES was 543 associated with both systolic BP and diastolic BP, the association was inverse U-shaped (Riva et 544 al. 2016), while Coulon also found significant associations for both systolic BP and diastolic BP 545 among African-American adults (Coulon et al. 2016). Taken together these studies suggest that 546 there is some variability in the relationship between neighbourhood SES and diastolic BP and 547 that unraveling these relationships will require further studies.

548 The finding of sex differences in the association between community SES and health have been 549 previously reported in studies from Jamaica (Cunningham-Myrie et al. 2015; Mullings et al. 550 2013). Cunningham-Myrie and colleagues (Cunningham-Myrie et al. 2015) found significant sex 551 interaction in the relationship between neighbourhood infrastructure score and the prevalence of 552 obesity, while Mullings and colleagues (Mullings et al. 2013) found that significant sex 553 differences in the relationship between prevalent depressive symptoms and neighbourhood 554 infrastructure and settlement pattern. In a study from Greenland, Riva and colleagues found that 555 the associations between neighbourhood SES and blood pressure appeared to be stronger in men 556 compared to women (Riva et al. 2016). These findings are consistent with several other studies

557 from our group that have shown sex-differences in the relationship between individual or 558 household level socioeconomic status and health outcomes (Ferguson et al. 2010a; Ferguson et 559 al. 2015; Ferguson et al. 2018; Ferguson et al. 2017; Ferguson et al. 2010b). This suggests that 560 sex may be an important effect modifier in the relationship between social factors and health and 561 therefore should be explored in studies evaluating these relationships. The associations found in 562 this study could be interpreted to suggest that education and wealth (high loadings in PCA-SES1) 563 may be protective for men, whereas poverty and crowding (as represented by unemployment and 
564 population density) may have important effects for women. This is supported by the findings of

565 Mullings and colleagues who found that for depressive symptoms in Jamaica, poor community

566 infrastructure was associated with increased risk among males, whereas, among females, residing

567 in informal unplanned (usually crowded) communities was associated with increased risk

568 (Mullings et al. 2013). It is possible that increased stress from living in poorer, tension-prone 569 environments, as well as higher levels of alcohol and tobacco use may contribute to the higher

570 blood pressure from lower SES for males, whereas household stressors related to crowding, lack

571 of financial resources contribute to higher blood pressure in females. These hypotheses would 572 need to be further explored in future studies.

573 The mechanisms underlying the relationship between neighbourhood SES and blood pressure

574 has not yet been fully elucidated. Broadly speaking, neighbourhood SES may influence health

575 through compositional effects (based on aggregate effect of individual risk factors), contextual

576 effects (group level effects beyond those due to risk factors) or environmental effects (Diez Roux

$577 \&$ Mair 2010). This involves the process of embodiment where social and psychological factors

578 in one's environment result in biological changes and are ultimately expressed as biological

579 characteristics (Krieger 2005). With regards to blood pressure, it has been suggested that

580 persistent vigilance in a setting of neighbourhood disorder or poor neighbourhood social

581 circumstances may induce changes in vascular reactivity which results in higher blood pressure

582 (Ewart et al. 2004). Another study found that agonistic striving (induced by challenges to

583 interpersonal influence and control) and subordination (due to social denigration, rejection and

584 mistreatment) are potential mechanisms through which neighbourhood stress may result in

585 hypertension (Ewart et al. 2014). Other studies have found associations between adverse

586 neighbourhood circumstances and reduced nocturnal blood pressure dipping (Euteneuer et al.

587 2014; Mellman et al. 2015). Taken together these studies suggest that neural regulation of blood

588 pressure may be altered by psychosocial stress induced by living in neighbourhoods with adverse 589 social and economic conditions.

590 Strengths and Limitations

591 This study had several strengths, including the fact that individual participant data for all three

592 studies were available and therefore we were able perform pooled analyses in the study. The

593 similarities in the source population, age range, and timing for each study the studies facilitated 
594 pooled analysis. While there was some evidence of heterogeneity between studies, this was seen 595 only for specific splines of the second PCA-SES variable and therefore would have little effect 596 on our conclusions. The studies in general had good response rates, and two were from 597 nationally representative samples, so that the findings can be considered as generalizable to the 598 Jamaican population. Another strength of this study is the use of PCA to derive socioeconomic 599 status scores thus taking into consideration several SES variables rather than only a few select 600 community characteristics.

601 Limitations of this study include the cross-sectional design which limit our ability to make causal 602 inferences. However, given the findings from other cross-sectional and longitudinal studies cited 603 above, our findings add to the literature on this subject and strengthens the consistency of the 604 associations reported. The study was also limited by the fact that we had missing data for some 605 variables, however we able to account for this by using multiple imputation analyses, assuming that data were missing at random. We assessed the effect of imputation on the findings by

607 608 609

622

623 624 performing complete case analyses, which showed findings which were very similar to those found when imputation was used, thus increasing our confidence in the findings reported. Another potential limitation was the possibility of the same individual being included in two (or three) of the studies. While some communities were included in more than one study, we thought that the probability of the same individual being selected was low, given the differences in inclusion criteria for each study and the fact that households were selected based on a random starting point in the national surveys. It is therefore unlikely that such duplication would have had any meaningful effect on our estimates. Finally, we were unable to use survey weights to adjust for probability of selection of participants in communities as these data were available for only one of the three studies used; however, given the fact that we were more focused on the associations between neighbourhood SES and blood pressure rather than obtaining estimates of population prevalence, we believe that this would have very little effect on our findings. This position is supported by Carle who found that there were only minimal differences, which did not change inferences, when comparing weighted vs. unweighted analyses for multilevel models using survey data. (Carle 2009).

Overall, we believe that the findings in this paper will make an important addition to the literature on the relationship between neighbourhoods and health, particularly in light of its focus 
625 on adolescents and young adults in an African origin developing country context. This will serve 626 as a catalyst for further research in this area and will help to inform our strategy for reducing the 627 adverse public health implications of hypertension.

628

\section{CONCLUSION}

630 We have demonstrated that higher neighbourhood SES was inversely associated with BP among 631 Jamaican youth and that there were sex differences in these associations. Findings from this 632 study suggest that the neighbourhood context may be an important factor in the aetiology of 633 hypertension and that interventions to address the growing public health challenges resulting 634 from hypertension should include evaluation of neighbourhoods. Further research in Jamaica and 635 similar populations is warranted to improve our understanding of the aetiology of elevated blood 636 pressure and to help in the development of appropriate interventions.

637

638 ACKNOWLEDGEMENTS

639 The authors acknowledge the contribution of the project staff (nurses, laboratory personnel, 640 administrative staff, and project assistants) and the individual study participants for their 641 contribution to the project. The authors also acknowledge the contribution of the Mona Geo642 Informatics Institute for its contribution with regards to the community socioeconomic 643 characteristics data. 


\section{REFERENCES}

645

646

Airaksinen J, Hakulinen C, Pulkki-Råback L, Lehtimäki T, Raitakari OT, Keltikangas-Järvinen

647

648

649

650

651

652

653

654

655

656

657

658

659

660

661

662

663

664

665

666

667

668

669

670

671

672

Babyak MA. 2004. What you see may not be what you get: a brief, nontechnical introduction to overfitting in regression-type models. Psychosomatic Medicine 66:411-421. 10.1097/01.psy.0000127692.23278.a9

Carle AC. 2009. Fitting multilevel models in complex survey data with design weights: Recommendations. BMC Medical Research Methodology 9:49. 10.1186/1471-2288-9-49

Chaix B, Bean K, Leal C, Thomas F, Havard S, Evans D, Jego B, and Pannier B. 2010. Individual/neighborhood social factors and blood pressure in the RECORD Cohort Study: which risk factors explain the associations? Hypertension 55:769-775. 10.1161/hypertensionaha.109.143206

Chaix B, Ducimetiere P, Lang T, Haas B, Montaye M, Ruidavets JB, Arveiler D, Amouyel P, Ferrieres J, Bingham A, and Chauvin P. 2008. Residential environment and blood pressure in the PRIME Study: is the association mediated by body mass index and waist circumference? Journal of Hypertension 26:1078-1084. 10.1097/HJH.0b013e3282fd991f 
673 Chen E, and Paterson LQ. 2006. Neighborhood, family, and subjective socioeconomic status:

674 How do they relate to adolescent health? Health Psychology 25:704-714. 10.1037/0278-

$675 \quad 6133.25 .6 .704$

676 Chen X, and Wang Y. 2008. Tracking of Blood Pressure From Childhood to Adulthood: A

677 Systematic Review and Meta-Regression Analysis. Circulation 117:3171-3180.

$678 \quad 10.1161 /$ circulationaha. 107.730366

679 Cho KH, Lee SG, Nam CM, Lee EJ, Jang SY, Lee SH, and Park EC. 2016. Disparities in 680 socioeconomic status and neighborhood characteristics affect all-cause mortality in 681 patients with newly diagnosed hypertension in Korea: a nationwide cohort study, 2002682 2013. Int J Equity Health 15:3. 10.1186/s12939-015-0288-2

683 Chobanian AV, Bakris GL, Black HR, Cushman WC, Green LA, Izzo JL, Jr., Jones DW, 684

685

686

687

688

689

690

691 Materson BJ, Oparil S, Wright JT, Jr., and Roccella EJ. 2003. The Seventh Report of the Joint National Committee on Prevention, Detection, Evaluation, and Treatment of High Blood Pressure: the JNC 7 report. JAMA 289:2560-2572.

Coulon SM, Wilson DK, Alia KA, and Van Horn ML. 2016. Multilevel Associations of Neighborhood Poverty, Crime, and Satisfaction With Blood Pressure in AfricanAmerican Adults. American Journal of Hypertension 29:90-95. 10.1093/ajh/hpv060

Cunningham-Myrie CA, Mabile E, Govia I, Younger NO, Tulloch-Reid MK, McFarlane S, Francis D, Gordon-Strachan G, Wilks R, Greene LG, Lyew-Ayee P, and Theall KP. 2018. Neighbourhood characteristics and cumulative biological risk: evidence from the

694 Jamaica Health and Lifestyle Survey 2008: a cross-sectional study. BMJ Open 8:e021952. 10.1136/bmjopen-2018-021952

Cunningham-Myrie CA, Theall KP, Younger NO, Mabile EA, Tulloch-Reid MK, Francis DK, McFarlane SR, Gordon-Strachan GM, and Wilks RJ. 2015. Associations between 698 neighborhood effects and physical activity, obesity, and diabetes: The Jamaica Health and Lifestyle Survey 2008. Journal of Clinical Epidemiology 68:970-978. 10.1016/j.jclinepi.2014.08.004

Diez Roux AV. 2016. Neighborhoods and Health: What Do We Know? What Should We Do? American Journal of Public Health 106:430-431. 10.2105/ajph.2016.303064

Diez Roux AV, and Mair C. 2010. Neighborhoods and health. Annals of the New York Academy of Sciences 1186:125-145. 10.1111/j.1749-6632.2009.05333.x 
704 Dinno A. 2009. Implementing Horn's Parallel Analysis for Principal Component Analysis and

705

706

707

708

709

710

711

712

713

714

715

716

717

718

719

720

721

722

723

724

725

726

727

728

729

730

731

732

733 Factor Analysis. The Stata Journal 9:291-298. 10.1177/1536867x0900900207

Duncan DT, and Kawachi I. 2018. Neighborhoods and Health: A Progress Report. In: Duncan DT, and Kawachi I, eds. Neighborhoods and Health. Second ed. New York: Oxford University Press.

Euteneuer F, Mills PJ, Pung MA, Rief W, and Dimsdale JE. 2014. Neighborhood problems and nocturnal blood pressure dipping. Health Psychology 33:1366-1372. 10.1037/hea0000004

Ewart CK, Elder GJ, and Smyth JM. 2014. How neighborhood disorder increases blood pressure in youth: agonistic striving and subordination. Journal of Behavioral Medicine 37:113126. $10.1007 / \mathrm{s} 10865-012-9467-4$

Ewart CK, Jorgensen RS, Schroder KE, Suchday S, and Sherwood A. 2004. Vigilance to a persisting personal threat: Unmasking cardiovascular consequences in adolescents with the Social Competence Interview. Psychophysiology 41:799-804. doi:10.1111/j.14698986.2004.00199.x

Fan AZ, Strasser SM, Zhang X, Fang J, and Crawford CG. 2015. State socioeconomic indicators and self-reported hypertension among US adults, 2011 behavioral risk factor surveillance system. Preventing Chronic Disease 12:E27. 10.5888/pcd12.140353

Felker-Kantor EA, Cunningham-Myrie C, Greene LG, Lyew-Ayee P, Atkinson U, Abel W, Clarke P, Anderson SG, and Theall KP. 2019. Neighborhood crime, disorder and substance use in the Caribbean context: Jamaica National Drug Use Prevalence Survey 2016. PloS One 14:e0224516. 10.1371/journal.pone.0224516

Ferguson TS, Francis DK, Tulloch-Reid MK, Younger NO, McFarlane SR, and Wilks RJ. 2011. An update on the burden of cardiovascular disease risk factors in Jamaica: findings from the Jamaica Health and Lifestyle Survey 2007-2008. The West Indian medical journal 60:422-428.

Ferguson TS, Tulloch-Reid MK, Younger NO, Knight-Madden JM, Samms-Vaughan M, Ashley D, Van den Broeck J, and Wilks RJ. 2010a. Prevalence of the metabolic syndrome and its components in relation to socioeconomic status among Jamaican young adults: a crosssectional study. BMC Public Health 10:307. 10.1186/1471-2458-10-307 
734 Ferguson TS, Younger-Coleman NO, Tulloch-Reid MK, Knight-Madden JM, Bennett NR,

735

736

737

738

739

740

741

742

743

744

745

746

747

748

749

750

751

752

753

754

755

756

757

758

759

760

761

762

763

764

Samms-Vaughan M, Ashley D, McCaw-Binns A, Molaodi OR, Cruickshank JK, Harding S, and Wilks RJ. 2015. Birth weight and maternal socioeconomic circumstances were inversely related to systolic blood pressure among Afro-Caribbean young adults. Journal of Clinical Epidemiology 68:1002-1009. 10.1016/j.jclinepi.2015.01.026

Ferguson TS, Younger-Coleman NOM, Tulloch-Reid MK, Bennett NR, Rousseau AE, KnightMadden JM, Samms-Vaughan ME, Ashley DE, and Wilks RJ. 2018. Factors associated with elevated blood pressure or hypertension in Afro-Caribbean youth: a cross-sectional study. PeerJ 6:e4385. 10.7717/peerj.4385

Ferguson TS, Younger-Coleman NOM, Tulloch-Reid MK, Hambleton IR, Francis DK, Bennett NR, McFarlane SR, Bidulescu A, MacLeish MY, Hennis AJM, Wilks RJ, Harris EN, and Sullivan LW. 2017. Educational Health Disparities in Cardiovascular Disease Risk Factors: Findings from Jamaica Health and Lifestyle Survey 2007-2008. Front Cardiovasc Med 4:28. 10.3389/fcvm.2017.00028

Ferguson TS, Younger N, Tulloch-Reid MK, Forrester TE, Cooper RS, Van den Broeck J, and Wilks RJ. 2010b. Prevalence of the metabolic syndrome in Jamaican adults and its relationship to income and education levels. West Indian Medical Journal 59:265-273.

Ferguson TS, Younger NO, Tulloch-Reid MK, Wright MB, Ward EM, Ashley DE, and Wilks RJ. 2008. Prevalence of prehypertension and its relationship to risk factors for cardiovascular disease in Jamaica: analysis from a cross-sectional survey. $B M C$ Cardiovascular Disorders 8:20. 10.1186/1471-2261-8-20

Gakidou E, Afshin A, Abajobir AA, Abate KH, Abbafati C, Abbas KM, Abd-Allah F, Abdulle AM, Abera SF, Aboyans V, Abu-Raddad LJ, Abu-Rmeileh NME, Abyu GY, Adedeji IA, Adetokunboh O, Afarideh M, Agrawal A, Agrawal S, Ahmadieh H, Ahmed MB, Aichour MTE, Aichour AN, Aichour I, Akinyemi RO, Akseer N, Alahdab F, Al-Aly Z, Alam K, Alam N, Alam T, Alasfoor D, Alene KA, Ali K, Alizadeh-Navaei R, Alkerwi Aa, Alla F, Allebeck P, Al-Raddadi R, Alsharif U, Altirkawi KA, Alvis-Guzman N, Amare AT, Amini E, Ammar W, Amoako YA, Ansari H, Antó JM, Antonio CAT, Anwari P, Arian N, Ärnlöv J, Artaman A, Aryal KK, Asayesh H, Asgedom SW, Atey TM, Avila-Burgos L, Avokpaho EFGA, Awasthi A, Azzopardi P, Bacha U, Badawi A, Balakrishnan K, Ballew SH, Barac A, Barber RM, Barker-Collo SL, Bärnighausen T, Barquera S,

Peer] reviewing PDF | (2019:10:42392:2:0:NEW 8 Aug 2020) 
Barregard L, Barrero LH, Batis C, Battle KE, Baumgarner BR, Baune BT, Beardsley J, Bedi N, Beghi E, Bell ML, Bennett DA, Bennett JR, Bensenor IM, Berhane A, Berhe DF, Bernabé E, Betsu BD, Beuran M, Beyene AS, Bhansali A, Bhutta ZA, Bicer BK, Bikbov B, Birungi C, Biryukov S, Blosser CD, Boneya DJ, Bou-Orm IR, Brauer M, Breitborde NJK, Brenner H, Brugha TS, Bulto LNB, Butt ZA, Cahuana-Hurtado L, Cárdenas R, Carrero JJ, Castañeda-Orjuela CA, Catalá-López F, Cercy K, Chang H-Y, Charlson FJ, Chimed-Ochir O, Chisumpa VH, Chitheer AA, Christensen H, Christopher DJ, Cirillo M, JA, Dandona L, Dandona R, das Neves J, Davey G, Davitoiu DV, Davletov K, de Courten B, Defo BK, Degenhardt L, Deiparine S, Dellavalle RP, Deribe K, Deshpande A, Dharmaratne SD, Ding EL, Djalalinia S, Do HP, Dokova K, Doku DT, Donkelaar Av, Dorsey ER, Driscoll TR, Dubey M, Duncan BB, Duncan S, Ebrahimi H, El-Khatib ZZ, Enayati A, Endries AY, Ermakov SP, Erskine HE, Eshrati B, Eskandarieh S, Esteghamati A, Estep K, Faraon EJA, Farinha CSeS, Faro A, Farzadfar F, Fay K, Feigin VL, Fereshtehnejad S-M, Fernandes JC, Ferrari AJ, Feyissa TR, Filip I, Fischer F, Fitzmaurice C, Flaxman AD, Foigt N, Foreman KJ, Frostad JJ, Fullman N, Fürst T, Furtado JM, Ganji M, Garcia-Basteiro AL, Gebrehiwot TT, Geleijnse JM, Geleto A, Gemechu BL, Gesesew HA, Gething PW, Ghajar A, Gibney KB, Gill PS, Gillum RF, Giref AZ, Gishu MD, Giussani G, Godwin WW, Gona PN, Goodridge A, Gopalani SV, Goryakin Y, Goulart AC, Graetz N, Gugnani HC, Guo J, Gupta R, Gupta T, Gupta V, Gutiérrez RA, Hachinski V, Hafezi-Nejad N, Hailu GB, Hamadeh RR, Hamidi S, Hammami M, Handal AJ, Hankey GJ, Hanson SW, Harb HL, Hareri HA, Hassanvand MS, Havmoeller R, Hawley C, Hay SI, Hedayati MT, Hendrie D, Heredia-Pi IB, Hernandez JCM, Hoek HW, Horita N, Hosgood HD, Hostiuc S, Hoy DG, Hsairi M, Hu G, Huang JJ, Huang H, Ibrahim NM, Iburg KM, Ikeda C, Inoue M, Irvine CMS, Jackson MD, Jacobsen KH, Jahanmehr N, Jakovljevic MB, Jauregui A, Javanbakht M, Jeemon P, Johansson LRK, Johnson CO, Jonas JB, Jürisson M, Kabir Z, Kadel R, Kahsay A, Kamal R, Karch A, Karema CK, Kasaeian A, Kassebaum NJ, Kastor A, Katikireddi SV, Kawakami N, Keiyoro PN, Kelbore SG, Kemmer L, Kengne AP, Kesavachandran CN, Khader YS, Khalil IA, Khan EA, Khang Y-H, Khosravi A, Khubchandani J, Kiadaliri AA, Kieling C, Kim JY, Kim YJ, Kim D, Kimokoti RW, Kinfu Y, Kisa A, Kissimova- 
796

797

798

799

800

801

802

803

804

805

806

807

808

809

810

811

812

813

814

815

816

817

818

819

820

821

822

823

824

825

826

Skarbek KA, Kivimaki M, Knibbs LD, Knudsen AK, Kopec JA, Kosen S, Koul PA, Koyanagi A, Kravchenko M, Krohn KJ, Kromhout H, Kumar GA, Kutz M, Kyu HH, Lal DK, Lalloo R, Lallukka T, Lan Q, Lansingh VC, Larsson A, Lee PH, Lee A, Leigh J, Leung J, Levi M, Levy TS, Li Y, Li Y, Liang X, Liben ML, Linn S, Liu P, Lodha R, Logroscino G, Looker KJ, Lopez AD, Lorkowski S, Lotufo PA, Lozano R, Lunevicius R, Macarayan ERK, Magdy Abd El Razek H, Magdy Abd El Razek M, Majdan M, Majdzadeh R, Majeed A, Malekzadeh R, Malhotra R, Malta DC, Mamun AA, Manguerra H, Mantovani LG, Mapoma CC, Martin RV, Martinez-Raga J, Martins-Melo FR, Mathur MR, Matsushita K, Matzopoulos R, Mazidi M, McAlinden C, McGrath JJ, Mehata S, Mehndiratta MM, Meier T, Melaku YA, Memiah P, Memish ZA, Mendoza W, Mengesha MM, Mensah GA, Mensink GBM, Mereta ST, Meretoja TJ, Meretoja A, Mezgebe HB, Micha R, Millear A, Miller TR, Minnig S, Mirarefin M, Mirrakhimov EM, Misganaw A, Mishra SR, Mohammad KA, Mohammed KE, Mohammed S, Mohan MBV, Mokdad AH, Monasta L, Montico M, Moradi-Lakeh M, Moraga P, Morawska L, Morrison SD, Mountjoy-Venning C, Mueller UO, Mullany EC, Muller K, Murthy GVS, Musa KI, Naghavi M, Naheed A, Nangia V, Natarajan G, Negoi RI, Negoi I, Nguyen CT, Nguyen QL, Nguyen TH, Nguyen G, Nguyen M, Nichols E, Ningrum DNA, Nomura M, Nong VM, Norheim OF, Norrving B, Noubiap JJN, Obermeyer CM, Ogbo FA, Oh I-H, Oladimeji O, Olagunju AT, Olagunju TO, Olivares PR, Olsen HE, Olusanya BO, Olusanya JO, Opio JN, Oren E, Ortiz A, Ota E, Owolabi MO, Pa M, Pacella RE, Pana A, Panda BK, Panda-Jonas S, Pandian JD, Papachristou C, Park E-K, Parry CD, Patten SB, Patton GC, Pereira DM, Perico N, Pesudovs K, Petzold M, Phillips MR, Pillay JD, Piradov MA, Pishgar F, Plass D, Pletcher MA, Polinder S, Popova S, Poulton RG, Pourmalek F, Prasad N, Purcell C, Qorbani M, Radfar A, Rafay A, Rahimi-Movaghar A, Rahimi-Movaghar V, Rahman MHU, Rahman MA, Rahman M, Rai RK, Rajsic S, Ram U, Rawaf S, Rehm CD, Rehm J, Reiner RC, Reitsma MB, Remuzzi G, Renzaho AMN, Resnikoff S, Reynales-Shigematsu LM, Rezaei S, Ribeiro AL, Rivera JA, Roba KT, Rojas-Rueda D, Roman Y, Room R, Roshandel G, Roth GA, Rothenbacher D, Rubagotti E, Rushton L, Sadat N, Safdarian M, Safi S, Safiri S, Sahathevan R, Salama J, Salomon JA, Samy AM, Sanabria JR, Sanchez-Niño MD, Sánchez-Pimienta TG, Santomauro D, Santos IS, Santric Milicevic MM, Sartorius B, Satpathy M, Sawhney M, Saxena S, 
827

828

829

830

831

832

833

834

835

836

837

838

839

840

841

842

843

844

845

846

847

848

849

850

851

852

853

854

855
Schmidt MI, Schneider IJC, Schutte AE, Schwebel DC, Schwendicke F, Seedat S, Sepanlou SG, Serdar B, Servan-Mori EE, Shaddick G, Shaheen A, Shahraz S, Shaikh MA, Shamsipour M, Shamsizadeh M, Shariful Islam SM, Sharma J, Sharma R, She J, Shen J, Shi P, Shibuya K, Shields C, Shiferaw MS, Shigematsu M, Shin M-J, Shiri R, Shirkoohi R, Shishani K, Shoman H, Shrime MG, Sigfusdottir ID, Silva DAS, Silva JP, Silveira DGA, Singh JA, Singh V, Sinha DN, Skiadaresi E, Slepak EL, Smith DL, Smith M, Sobaih BHA, Sobngwi E, Soneji S, Sorensen RJD, Sposato LA, Sreeramareddy CT, Srinivasan V, Steel N, Stein DJ, Steiner C, Steinke S, Stokes MA, Strub B, Subart M, Sufiyan MB, Suliankatchi RA, Sur PJ, Swaminathan S, Sykes BL, Szoeke CEI, TabarésSeisdedos R, Tadakamadla SK, Takahashi K, Takala JS, Tandon N, Tanner M, Tarekegn YL, Tavakkoli M, Tegegne TK, Tehrani-Banihashemi A, Terkawi AS, Tesssema B, Thakur JS, Thamsuwan O, Thankappan KR, Theis AM, Thomas ML, Thomson AJ, Thrift AG, Tillmann T, Tobe-Gai R, Tobollik M, Tollanes MC, Tonelli M, Topor-Madry R, Torre A, Tortajada M, Touvier M, Tran BX, Truelsen T, Tuem KB, Tuzcu EM, Tyrovolas S, Ukwaja KN, Uneke CJ, Updike R, Uthman OA, van Boven JFM, Varughese S, Vasankari T, Veerman LJ, Venkateswaran V, Venketasubramanian N, Violante FS, Vladimirov SK, Vlassov VV, Vollset SE, Vos T, Wadilo F, Wakayo T, Wallin MT, Wang Y-P, Weichenthal S, Weiderpass E, Weintraub RG, Weiss DJ, Werdecker A, Westerman R, Whiteford HA, Wiysonge CS, Woldeyes BG, Wolfe CDA, Woodbrook R, Workicho A, Xavier D, Xu G, Yadgir S, Yakob B, Yan LL, Yaseri M, Yimam HH, Yip P, Yonemoto N, Yoon S-J, Yotebieng M, Younis MZ, Zaidi Z, Zaki MES, Zavala-Arciniega L, Zhang X, Zimsen SRM, Zipkin B, Zodpey S, Lim SS, and Murray CJL. 2017. Global, regional, and national comparative risk assessment of 84 behavioural, environmental and occupational, and metabolic risks or clusters of risks, 1990 - 2016: a systematic analysis for the Global Burden of Disease Study 2016. The Lancet 390:1345-1422. 10.1016/S0140-6736(17)32366-8

Graham JW, Olchowski AE, and Gilreath TD. 2007. How many imputations are really needed? Some practical clarifications of multiple imputation theory. Prev Sci 8:206-213. $10.1007 / \mathrm{s} 11121-007-0070-9$ 
856 Greenland S, Daniel R, and Pearce N. 2016. Outcome modelling strategies in epidemiology:

857 traditional methods and basic alternatives. International Journal of Epidemiology 45:565$858 \quad 575.10 .1093 / \mathrm{ije} / \mathrm{dyw} 040$

859 Greenland S, and Pearce N. 2015. Statistical Foundations for Model-Based Adjustments. Annual 860 Review of Public Health 36:89-108. 10.1146/annurev-publhealth-031914-122559

861 Griffiths PL, Sheppard ZA, Johnson W, Cameron N, Pettifor JM, and Norris SA. 2012.

862

863

864

865 866

867

868

869

870

871

872

873

874

875

876

877

878

879

880

881

882

883

884 885

Associations between household and neighbourhood socioeconomic status and systolic blood pressure among urban South African adolescents. Journal of Biosocial Science 44:433-458. 10.1017/s0021932012000107

Hair J, Black B, Babin B, Anderson R, and Tatham R. 2006. Multivariate Data Analysis. Upper Saddle River, N.J.: Pearson.

Hamilton L. 2013. Statistics with Stata Updated for version 12. Boston, USA: Brooks/Cole.

Harrell FE. 2015. General Aspects of Fitting Regression Models. Regression Modeling Strategies: With Applications to Linear Models, Logistic and Ordinal Regression, and Survival Analysis. Second Edition ed. Switzerland: Springer.

Hayton JC, Allen DG, and Scarpello V. 2004. Factor Retention Decisions in Exploratory Factor Analysis: a Tutorial on Parallel Analysis. Organizational Research Methods 7:191-205. $10.1177 / 1094428104263675$

Hofelmann DA, Antunes JL, Santos Silva DA, and Peres MA. 2012. Is income area level associated with blood pressure in adults regardless of individual-level characteristics? A multilevel approach. Health Place 18:971-977. 10.1016/j.healthplace.2012.06.010

Ip P, Ho FK, So HK, Chan DF, Ho M, Tso W, and Nelson EA. 2016. Socioeconomic Gradient in Childhood Obesity and Hypertension: A Multilevel Population-Based Study in a Chinese Community. PloS One 11:e0156945. 10.1371/journal.pone.0156945

Jivraj S, Murray ET, Norman P, and Nicholas O. 2019. The impact of life course exposures to neighbourhood deprivation on health and well-being: a review of the long-term neighbourhood effects literature. European Journal of Public Health. 10.1093/eurpub/ckz153

Krieger N. 2005. Embodiment: a conceptual glossary for epidemiology. Journal of Epidemiology and Community Health 59:350-355. 10.1136/jech.2004.024562 
886 Kwok MK, Subramanian SV, Leung GM, and Schooling CM. 2015. Household income and 887 adolescent blood pressure in a Chinese birth cohort: "Children of 1997". Social Science 888 and Medicine 144:88-95. 10.1016/j.socscimed.2015.09.012

889 890

891

892

893

894

895

896

897

898

899

900

901

902

903

904

905

906

907

908

909

910

911

912

913

914

915

Leng B, Jin Y, Li G, Chen L, and Jin N. 2015. Socioeconomic status and hypertension: a metaanalysis. Journal of Hypertension 33:221-229. 10.1097/hjh.0000000000000428

Lewington S, Clarke R, Qizilbash N, Peto R, and Collins R. 2002. Age-specific relevance of usual blood pressure to vascular mortality: a meta-analysis of individual data for one million adults in 61 prospective studies. Lancet 360:1903-1913.

Liu L, Nunez AE, Yu X, Yin X, and Eisen HJ. 2013. Multilevel and spatial-time trend analyses of the prevalence of hypertension in a large urban city in the USA. Journal of Urban Health 90:1053-1063. 10.1007/s11524-013-9815-x

Lohr SL. 1999. Sampling: Design and Analysis. CA: Duxbury Press.

Lowe GA, Lipps G, Gibson RC, Halliday S, Morris A, Clarke N, and Wilson RN. 2014. Neighbourhood factors and depression among adolescents in four Caribbean countries. PloS One 9:e95538. 10.1371/journal.pone.0095538

Macintyre S, and Ellaway A. 2003. Neighborhoods and Health: An Overview. In: Kawachi I, and Berkman L, eds. Neighborhoods and Health. Oxford Scholarship Online: Oxford University Press.

Macintyre S, Ellaway A, and Cummins S. 2002. Place effects on health: how can we conceptualise, operationalise and measure them? Social Science and Medicine 55:125139. https://doi.org/10.1016/S0277-9536(01)00214-3

Mackenbach JP, Stirbu I, Roskam A-JR, Schaap MM, Menvielle G, Leinsalu M, and Kunst AE. 2008. Socioeconomic Inequalities in Health in 22 European Countries. New England Journal of Medicine 358:2468-2481. doi:10.1056/NEJMsa0707519

Marshall A, Altman DG, Holder RL, and Royston P. 2009. Combining estimates of interest in prognostic modelling studies after multiple imputation: current practice and guidelines. BMC Medical Research Methodology 9:57. 10.1186/1471-2288-9-57

McCaw-Binns A, Ashley D, Samms-Vaughan M, Wilks R, Ferguson T, Younger N, Reece JA, Tulloch-Reid M, and Foster-Williams K. 2011. Cohort profile: the Jamaican 1986 birth cohort study. International Journal of Epidemiology 40:1469-1476. 10.1093/ije/dyq149 
916 McFarlane S, Younger N, Francis D, Gordon-Strachan G, and Wilks R. 2014. Risk behaviours

917 and adolescent depression in Jamaica. International Journal of Adolescence and Youth $918 \quad 19: 458-467.10 .1080 / 02673843.2012 .751041$

919 McGrath JJ, Matthews KA, and Brady SS. 2006. Individual versus neighborhood socioeconomic 920 status and race as predictors of adolescent ambulatory blood pressure and heart rate. Social Science and Medicine 63:1442-1453. 10.1016/j.socscimed.2006.03.019

922

923

924

925

926

927

928

929

930

931

932

933

934

935

936

937

938

939

940

941

942

943

944

945

946

Mellman TA, Brown TS, Kobayashi I, Abu-Bader SH, Lavela J, Altaee D, McLaughlin L, and Randall OS. 2015. Blood Pressure Dipping and Urban Stressors in Young Adult African Americans. Annals of Behavioral Medicine 49:622-627. 10.1007/s12160-014-9684-X

Morenoff JD, House JS, Hansen BB, Williams DR, Kaplan GA, and Hunte HE. 2007. Understanding social disparities in hypertension prevalence, awareness, treatment, and control: the role of neighborhood context. Social Science and Medicine 65:1853-1866. 10.1016/j.socscimed.2007.05.038

Mujahid MS, Diez Roux AV, Cooper RC, Shea S, and Williams DR. 2011. Neighborhood stressors and race/ethnic differences in hypertension prevalence (the Multi-Ethnic Study of Atherosclerosis). American Journal of Hypertension 24:187-193. 10.1038/ajh.2010.200

Mullings JA, McCaw-Binns AM, Archer C, and Wilks R. 2013. Gender differences in the effects of urban neighborhood on depressive symptoms in Jamaica. Revista Panamericana de Salud Publica 34:385-392.

Murakami K, Sasaki S, Takahashi Y, and Uenishi K. 2010. Neighborhood socioeconomic status in relation to dietary intake and insulin resistance syndrome in female Japanese dietetic students. Nutrition 26:508-514. 10.1016/j.nut.2009.08.025

NCD Risk Factor Collaboration (NCD-RisC). 2017. Worldwide trends in blood pressure from 1975 to 2015: a pooled analysis of 1479 population-based measurement studies with 19.1 million participants. Lancet 389:37-55. 10.1016/s0140-6736(16)31919-5

Nguyen CD, Carlin JB, and Lee KJ. 2017. Model checking in multiple imputation: an overview and case study. Emerging Themes in Epidemiology 14:8. 10.1186/s12982-017-0062-6

Oakes JM, Andrade KE, Biyoow IM, and Cowan LT. 2015. Twenty Years of Neighborhood Effect Research: An Assessment. Current Epidemiology Reports 2:80-87. $10.1007 / \mathrm{s} 40471-015-0035-7$ 
947 Peduzzi P, Concato J, Kemper E, Holford TR, and Feinstein AR. 1996. A simulation study of the 948 number of events per variable in logistic regression analysis. Journal of Clinical 949 Epidemiology 49:1373-1379. 10.1016/S0895-4356(96)00236-3

950 Pemberton S, and Humphris R. 2016. Locality, neighbourhood and health: a literature review:

951 Birmingham: Institute for Research into Superdiversity.

952 Planning Institute of Jamaica. 2006. Spatial Boundaries of Jamaica.

953 Ribeiro AI. 2018. Public health: why study neighborhoods? Porto Biomedical Journal 3:e16. $954 \quad 10.1016 / j . p b j .0000000000000016$

955 Ribeiro AI, Fraga S, Kelly-Irving M, Delpierre C, Stringhini S, Kivimaki M, Joost S, Guessous I, 956 Gandini M, Vineis P, and Barros H. 2019. Neighbourhood socioeconomic deprivation 957 958 and allostatic load: a multi-cohort study. Scientific Reports 9:8790. 10.1038/s41598-01945432-4

959

960

961

962

963

964

965

966

967

968

969

970

971

972

973

974

975

976

977

Riva M, Larsen CV, and Bjerregaard P. 2016. Association between individual-level and community-level socio-economic status and blood pressure among Inuit in Greenland. International Journal of Circumpolar Health 75:32757. 10.3402/ijch.v75.32757

Sprung MR, Faulkner LMD, Evans MK, Zonderman AB, and Waldstein SR. 2019. Neighborhood crime is differentially associated with cardiovascular risk factors as a function of race and sex. J Public Health Res 8:1643. 10.4081/jphr.2019.1643

StataCorp. 2015a. Stata Base Reference Manual Release 14. College Station, Texas: Stata Press. StataCorp. 2015b. Stata Multiple Imputation Reference Manual Release 14. College Station, Texas: Stata Press.

Thompson DS, Younger-Coleman N, Lyew-Ayee P, Greene LG, Boyne MS, and Forrester TE. 2017. Socioeconomic factors associated with severe acute malnutrition in Jamaica. PloS One 12:e0173101. 10.1371/journal.pone.0173101

Unger E, Diez-Roux AV, Lloyd-Jones DM, Mujahid MS, Nettleton JA, Bertoni A, Badon SE, Ning H, and Allen NB. 2014. Association of neighborhood characteristics with cardiovascular health in the multi-ethnic study of atherosclerosis. Circulation: Cardiovascular Quality and Outcomes 7:524-531. 10.1161/circoutcomes.113.000698

Vasan RS, Larson MG, Leip EP, Evans JC, O'Donnell CJ, Kannel WB, and Levy D. 2001. Impact of high-normal blood pressure on the risk of cardiovascular disease. New England Journal of Medicine 345:1291-1297. 10.1056/NEJMoa003417 
978 Whelton PK, Carey RM, Aronow WS, Casey DE, Collins KJ, Dennison Himmelfarb C, 979 DePalma SM, Gidding S, Jamerson KA, Jones DW, MacLaughlin EJ, Muntner P, 980 Ovbiagele B, Smith SC, Spencer CC, Stafford RS, Taler SJ, Thomas RJ, Williams KA, 981 Williamson JD, and Wright JT. 2018. 2017

982

983

984

985

986

987

988

989

990

991

992

993 ACC/AHA/AAPA/ABC/ACPM/AGS/APhA/ASH/ASPC/NMA/PCNA Guideline for the Prevention, Detection, Evaluation, and Management of High Blood Pressure in Adults. Hypertension 71:e12-e115. 10.1161/hyp.0000000000000065

White IR, Royston P, and Wood AM. 2011. Multiple imputation using chained equations: Issues and guidance for practice. Statistics in Medicine 30:377-399. 10.1002/sim.4067

Wilks R, Younger N, McFarlane S, Francis D, and Van Den Broeck J. 2007. JAMAICAN YOUTH RISK AND RESILIENCY BEHAVIOUR SURVEY 2006. The University of the West Indies.

Wilks R, Younger N, Tulloch-Reid M, McFarlane S, and Francis D. 2008. Jamaica Health and Lifestyle Survey 2007-8 Technical Report. University of the West Indies website.

Wood AM, White IR, and Royston P. 2008. How should variable selection be performed with multiply imputed data? Statistics in Medicine 27:3227-3246. 10.1002/sim.3177 


\section{Table $\mathbf{1}$ (on next page)}

Summary statistics for participant and community characteristics by study 
Table 1: Summary statistics for participant and community characteristics by study

\begin{tabular}{|c|c|c|c|c|c|}
\hline Characteristics & $\begin{array}{c}\text { All } \\
\text { Participants } \\
\text { N=2556 }\end{array}$ & $\begin{array}{c}1986 \text { Birth } \\
\text { Cohort } \\
\text { n }=893\end{array}$ & $\begin{array}{c}\text { Youth } \\
\text { Risk } \\
\text { Survey } \\
\text { n=1200 }\end{array}$ & $\begin{array}{c}\text { Jamaica } \\
\text { Health \& } \\
\text { Lifestyle } \\
\text { Survey } \\
\text { n = 463 }\end{array}$ & P-value \\
\hline & Mean (SD) & Mean (SD) & Mean (SD) & Mean (SD) & \\
\hline Age (years) & $17.9(2.0)$ & $18.8(0.6)$ & $16.5(1.3)$ & $19.9(2.7)$ & $<0.001$ \\
\hline Height $(\mathrm{cm})$ & $169.0(9.4)$ & $169.6(9.1)$ & $167.0(9.7)$ & $167.4(8.8)$ & $<0.001$ \\
\hline Weight (kg) & $64.5(14.6)$ & $66.4(15.6)$ & $62.1(13.0)$ & $67.1(15.7)$ & $<0.001$ \\
\hline Body mass index $\left(\mathrm{kg} / \mathrm{m}^{2}\right)$ & $22.9(6.1)$ & $23.0(5.0)$ & $22.3(4.7)$ & $24.0(5.8)$ & $<0.001$ \\
\hline Systolic BP (mmHg) & $111.5(10.8)$ & $110.4(10.1)$ & $111.4(10.5)$ & $113.9(12.3)$ & $<0.001$ \\
\hline Diastolic BP (mmHg) & $69.8(10.2)$ & $67.9(9.8)$ & $70.4(10.1)$ & $71.8(10.5)$ & $<0.001$ \\
\hline Waist circumference $(\mathrm{cm})$ & $73.6(10.9)$ & $74.5(11.5)$ & $71.6(9.0)$ & $77.1(13.0)$ & $<0.001$ \\
\hline Fasting glucose (mmol/l) & $4.0(1.2)$ & $4.6(0.5)$ & $3.5(1.2)$ & $4.1(1.6)$ & $<0.001$ \\
\hline PCA-SES Component 1 (z-score) & $0.01(1.0)$ & $0.37(0.98)$ & $-0.12(0.99)$ & $0.19(0.86)$ & $<0.001$ \\
\hline \multirow[t]{2}{*}{ PCA SES Component 2 (z-score) } & $0.004(1.01)$ & $0.08(1.15)$ & $-0.01(0.93)$ & $-0.11(0.90)$ & $<0.001$ \\
\hline & n $(\%)$ & n $(\%)$ & n $(\%)$ & n $(\%)$ & \\
\hline Sex & & & & & $<0.001$ \\
\hline Female & $1446(56.6)$ & $485(54.3)$ & $657(54.8)$ & $304(65.7)$ & \\
\hline Male & $1110(43.4)$ & $408(45.7)$ & $543(45.3)$ & $159(34.3)$ & \\
\hline Elevated BP/HTN (BP $\geq 120 / 80$ mmHg) & $749(29.3)$ & $188(21.1)$ & $388(32.3)$ & $173(37.4)$ & $<0.001$ \\
\hline Body Mass Index Category & & & & & $<0.001$ \\
\hline Underweight & $322(12.6)$ & $94(10.6)$ & $181(15.1)$ & $47(10.3)$ & \\
\hline Normal weight & $1615(63.4)$ & $575(64.5)$ & $775(64.8)$ & $264(57.8)$ & \\
\hline Overweight & $400(15.7)$ & $149(16.7)$ & $169(14.1)$ & $82(17.9)$ & \\
\hline Obesity & $209(8.2)$ & $73(8.2)$ & $72(6.0)$ & $64(14.0)$ & \\
\hline Household Possessions Category & & & & & 0.012 \\
\hline Lower Third & $913(35.7)$ & $350(39.2)$ & $417(34.8)$ & $146(31.5)$ & \\
\hline Middle Third & $894(35.0)$ & $300(33.6)$ & $437(36.4)$ & $157(33.9)$ & \\
\hline Upper Third & $748(29.3)$ & $242(27.1)$ & $346(28.8)$ & $160(34.6)$ & \\
\hline Fast Food consumption & & & & & $<0.001$ \\
\hline$<=2$ times/week & $2045(80.7 \%)$ & $687(78.0)$ & $1004(80.4)$ & $354(76.5)$ & \\
\hline 3-4 times/week & $302(11.9)$ & $122(13.8)$ & $105(8.8)$ & $75(16.2)$ & \\
\hline$>=5$ times $/$ week & $186(7.3)$ & $72(8.2)$ & $80(6.7)$ & $34(7.3)$ & \\
\hline Physical Activity & & & & & $<0.001$ \\
\hline High & $902(35.3)$ & $215(24.1)$ & $564(47.0)$ & $123(26.6)$ & \\
\hline Moderate & $747(29.2)$ & $373(41.8)$ & $267(22.5)$ & $107(23.1)$ & \\
\hline Low & $906(35.5)$ & $304(34.1)$ & $369(30.8)$ & $233(50.3)$ & \\
\hline
\end{tabular}

P-values are for overall difference in mean or proportions across the three studies using analysis of variance for coßtinuous variables and Chi-squared tests for categorical variables.

$\mathrm{SD} 4=$ standard deviation; $\mathrm{BP}=$ blood pressure; $\mathrm{PCA}=$ principal component analysis; $\mathrm{SES}=$ socioeconomic status

PC5A Derived SES category 1 loads highly positive for proportion of population with tertiary education, larger house size an $\$$ higher population density and strongly negative for poverty and dependency ratio. Higher values indicate higher SES. PCA Derived SES category 2 loads highly positive for unemployment and population density, and strongly negative for ho\&se size. Higher values indicate lower SES. 
Table 2 (on next page)

Summary statistics for participant and community characteristics by blood pressure category 
1 Table 2: Summary statistics for participant and community characteristics by blood

2 pressure category

\begin{tabular}{|c|c|c|c|}
\hline Characteristics & $\begin{array}{c}\text { Normal Blood } \\
\text { Pressure } \\
\begin{array}{c}\text { (BP }<\mathbf{1 2 0} / 80 ~ \mathbf{~ m m H}) \\
\mathbf{n}=\mathbf{1 8 0 7}\end{array}\end{array}$ & $\begin{array}{c}\text { Elevated Blood } \\
\text { Pressure or } \\
\text { Hypertension } \\
\text { (BP } \geq \mathbf{1 2 0} / 80 \mathrm{mmHg}) \\
\mathrm{n}=\mathbf{7 4 9} \\
\end{array}$ & P-value \\
\hline & mean (SD) & mean (SD) & \\
\hline Age (years) & $17.9(2.0)$ & $18.0(2.2)$ & 0.543 \\
\hline Weight $(\mathrm{kg})$ & $62.7(13.3)$ & $68.8(16.7)$ & $<0.001$ \\
\hline Height $(\mathrm{cm})$ & $167.2(9.2)$ & $169.9(9.7)$ & $<0.001$ \\
\hline Body mass index $\left(\mathrm{kg} / \mathrm{m}^{2}\right)$ & $22.4(4.7)$ & $23.9(5.8)$ & $<0.001$ \\
\hline Systolic blood pressure (mmHg) & $107.0(7.5)$ & $122.5(9.6)$ & $<0.001$ \\
\hline Diastolic blood pressure $(\mathrm{mmHg})$ & $66.7(8.2)$ & $77.4(10.4)$ & $<0.001$ \\
\hline Waist circumference $(\mathrm{cm})$ & $72.5(10.1)$ & $76.4(12.4)$ & $<0.001$ \\
\hline Fasting glucose $(\mathrm{mmol} / \mathrm{l})$ & $4.0(1.2)$ & $4.1(1.3)$ & 0.101 \\
\hline PCA-SES Component 1 (z-score) & $0.08(1.02)$ & $-0.16(0.94)$ & $<0.001$ \\
\hline \multirow[t]{2}{*}{ PCA SES Component 2 (z-score) } & $0.02(1.05)$ & $-0.04(0.88)$ & 0.170 \\
\hline & n (\%) & n (\%) & \\
\hline Sex & & & $<0.001$ \\
\hline Female & $1112(61.5)$ & $334(44.6)$ & \\
\hline Male & $695(28.5)$ & $415(55.4)$ & \\
\hline Body Mass Index Category & & & $<0.001$ \\
\hline Underweight & $250(13.9)$ & $72(9.6)$ & \\
\hline Normal weight & $1162(64.7)$ & $453(60.5)$ & \\
\hline Overweight & $272(15.1)$ & $128(17.1)$ & \\
\hline Obesity & $113(6.3)$ & $96(12.8)$ & \\
\hline Household Possessions Category & & & 0.079 \\
\hline Lower Third & $639(35.4)$ & $274(36.6)$ & \\
\hline Middle Third & $616(34.1)$ & $278(37.2)$ & \\
\hline Upper Third & $552(30.6)$ & $196(26.2)$ & \\
\hline Fast Food consumption & & & 0.058 \\
\hline$<=2$ times/week & $1428(79.6)$ & $617(83.6)$ & \\
\hline 3-4 times/week & $225(12.5)$ & $77(10.4)$ & \\
\hline$>=5$ times $/$ week & $142(7.9)$ & $44(6.0)$ & \\
\hline Physical Activity & & & $<0.001$ \\
\hline High & $586(32.4)$ & $316(42.3)$ & \\
\hline Moderate & $541(29.9)$ & $206(27.5)$ & \\
\hline Low & $680(37.6)$ & $226(30.2)$ & \\
\hline
\end{tabular}

P-values are for difference in mean or proportions across the blood pressure categories using t-test for continuous variables and Chi-squared tests for categorical variables. $\mathrm{SD}=$ standard deviation; $\mathrm{BP}=$ blood pressure; PCA = principal component analysis; $\mathrm{SES}=$ socioeconomic status

PCA Derived SES category 1 loads highly positive for proportion of population with tertiary education, larger house size and higher population density and strongly negative for poverty and dependency ratio. Higher values indicate higher SES

PCA Derived SES category 2 loads highly positive for unemployment and population density, and strongly negative for house size. Higher values indicate lower SES. 


\section{Table 3 (on next page)}

Coefficients for association with systolic blood pressure for individual and community characteristics for male and female participants in bivariate regression model 
1 Table 3: Coefficients for association with systolic blood pressure for individual and community

2 characteristics for male and female participants in bivariate regression model

\begin{tabular}{|c|c|c|c|c|}
\hline Characteristics & $\begin{array}{c}\text { Males } \\
\mathrm{N}=1110 \\
\beta \text {-coefficient }(95 \% \\
\text { CI) }\end{array}$ & $\begin{array}{c}P \text { - } \\
\text { value }\end{array}$ & $\begin{array}{c}\text { Females } \\
n=1446 \\
\beta \text {-coefficient }(95 \% \\
\text { CI) }\end{array}$ & $\begin{array}{c}\text { P- } \\
\text { value }\end{array}$ \\
\hline PCA SES Component 1 (z-score) & $-1.45(-1.82,-1.07)$ & $<0.001$ & $-1.30(-2.16,-0.44)$ & 0.003 \\
\hline \multicolumn{5}{|l|}{ PCA SES Component 2 (z-score) } \\
\hline Spline $1(z$-score $<-1)$ & $1.73(-0.14,3.59)$ & 0.070 & $2.74(0.29,5.20)$ & 0.028 \\
\hline Spline 2 (z-score -1 to 0$)$ & $2.58(0.41,4.76)$ & 0.020 & $3.51(2.28,4.75)$ & $<0.001$ \\
\hline Spline 3 (z-score $>0$ to 1 ) & $0.55(-1.98,3.08)$ & 0.668 & $0.02(-1.82,1.86)$ & 0.983 \\
\hline Spline 4 (z-score $>1)$ & $0.11(-0.15,0.38)$ & 0.393 & $-0.46(-0.87,-0.05)$ & 0.027 \\
\hline Age (years) & $1.08(0.64,1.54)$ & $<0.001$ & $0.40(0.002,0.79)$ & 0.049 \\
\hline Body mass index (z-score) & $2.63(2.01,3.26)$ & $<0.001$ & $1.87(1.47,2.27)$ & $<0.001$ \\
\hline Fasting glucose $(\mathrm{mmol} / \mathrm{l})$ & $1.24(-0.15,2.63)$ & 0.080 & $0.45(0.02,0.88)$ & 0.042 \\
\hline \multicolumn{5}{|l|}{ Household Possessions Category } \\
\hline Lower Third & Reference category & & Reference category & \\
\hline Middle Third & $-1.11(-2.22,-0.002)$ & 0.050 & $-0.46(-1.31,0.39)$ & 0.285 \\
\hline Upper Third & $-0.84(-2.88,1.20)$ & 0.418 & $-1.59(-2.60,-0.58)$ & 0.002 \\
\hline \multicolumn{5}{|l|}{ Fast Food consumption } \\
\hline$<=2$ times/week & Reference category & & Reference category & \\
\hline 3-4 times/week & $0.46(-0.79,1.72)$ & 0.468 & $-1.38(-2.34,-0.42)$ & 0.005 \\
\hline$>=5$ times $/$ week & $-0.86(-2.93,1.21)$ & 0.418 & $-0.43(-1.63,0.78)$ & 0.650 \\
\hline \multicolumn{5}{|l|}{ Physical Activity } \\
\hline High & Reference category & & Reference category & \\
\hline Moderate & $0.24(-1.01,1.49)$ & 0.704 & $-0.06(-1.71,1.59)$ & 0.943 \\
\hline Low & $-1.57(-3.34,0.20)$ & 0.082 & $-0.24(-1.60,1.13)$ & 0.735 \\
\hline
\end{tabular}

$3 \quad$ PCA $=$ Principal Components Analysis; SES = socioeconomic status

4 P-values from three level linear mixed effect models in Stata. Level 1 - individual study participants;

5 level 2 -communities in which participant lived; level 3 - parish in which community was situated.

6 Models used multiple imputation to account for missing data and used robust standard errors. 


\section{Table 4 (on next page)}

Coefficients for association with diastolic blood pressure for individual and community characteristics for male and female participants in bivariate regression model 
1 Table 4: Coefficients for association with diastolic blood pressure for individual and 2 community characteristics for male and female participants in bivariate regression model

\begin{tabular}{|c|c|c|c|c|}
\hline Characteristics & $\begin{array}{c}\text { Males } \\
\mathrm{N}=\mathbf{1 1 1 0} \\
\beta \text {-coefficient }(95 \% \\
\text { CI) }\end{array}$ & $\begin{array}{c}\text { P- } \\
\text { value }\end{array}$ & $\begin{array}{c}\text { Females } \\
n=1446 \\
\beta \text {-coefficient }(95 \% \\
\text { CI) }\end{array}$ & $\begin{array}{c}\text { P- } \\
\text { value }\end{array}$ \\
\hline PCA SES Component 1 (z-score) & $-0.14(-0.91,0.63)$ & 0.720 & $0.15(-1.22,1.53)$ & 0.826 \\
\hline \multicolumn{5}{|l|}{ PCA SES Component 2 (z-score) } \\
\hline Spline $1(\mathrm{z}$-score $<-1)$ & $-2.73(-4.10,-1.36)$ & $<0.001$ & $0.42(-1.49,2.34)$ & 0.665 \\
\hline Spline 2 (z-score -1 to 0$)$ & $0.47(-0.66,1.61)$ & 0.412 & $-0.57(-2.23,1.09)$ & 0.500 \\
\hline Spline 3 (z-score $>0$ to 1$)$ & $-1.21(-2.67,0.26)$ & 0.107 & $-1.41(-2.18,-0.64)$ & $<0.001$ \\
\hline Spline $4($ z-score $>1)$ & $-0.13(-0.42,0.17)$ & 0.396 & $-0.14(-0.45,0.18)$ & 0.399 \\
\hline Age (years) & $0.67(0.16,1.17)$ & 0.010 & $0.17(-0.12,0.47)$ & 0.252 \\
\hline Body mass index (z-score) & $0.55(-0.46,1.56)$ & 0.286 & $0.81(0.29,1.32)$ & 0.002 \\
\hline Fasting glucose $(\mathrm{mmol} / \mathrm{l})$ & $0.41(-0.71,1.53)$ & 0.475 & $0.31(-0.18,0.79)$ & 0.215 \\
\hline \multicolumn{5}{|l|}{ Household Possessions Category } \\
\hline Lower Third & Reference category & & Reference category & \\
\hline Middle Third & $-0.59(-1.90,0.71)$ & 0.372 & $0.40(-0.38,1.19)$ & 0.311 \\
\hline Upper Third & $-0.51(-1.55,0.54)$ & 0.343 & $-0.27(-1.71,1.17)$ & 0.709 \\
\hline \multicolumn{5}{|l|}{ Fast Food consumption } \\
\hline$<=2$ times $/$ week & Reference category & & Reference category & \\
\hline 3-4 times/week & $0.43(-1.18,2.04)$ & 0.602 & $0.05(-0.93,1.04)$ & 0.916 \\
\hline$>=5$ times $/$ week & $1.26(-0.56,3.08)$ & 0.174 & $-0.84(-2.25,0.56)$ & 0.241 \\
\hline \multicolumn{5}{|l|}{ Physical Activity } \\
\hline High & Reference category & & Reference category & \\
\hline Moderate & $0.59(-0.59,1.77)$ & 0.329 & $-0.15(-0.86,0.56)$ & 0.683 \\
\hline Low & $-0.76(-2.54,1.01)$ & 0.399 & $-0.97(-1.85,-0.10)$ & 0.029 \\
\hline
\end{tabular}

$3 \quad \mathrm{PCA}=$ Principal Components Analysis; $\mathrm{SES}=$ socioeconomic status

4 P-values from three level linear mixed effect models in Stata. Level 1 - individual study participants;

5 level 2 - communities in which participant lived; level 3 - parish in which community was situated.

6 Models used multiple imputation to account for missing data and used robust standard errors. 


\section{Table 5 (on next page)}

Multivariable models for association between systolic blood pressure and neighbourhood socioeconomic status for male and female participants 
Table 5: Multivariable models for association between systolic blood pressure and neighbourhood socioeconomic status for male and female participants

\begin{tabular}{|c|c|c|c|c|c|c|}
\hline \multirow{2}{*}{$\begin{array}{l}\text { Characteristics } \\
\text { MALES }\end{array}$} & \multicolumn{2}{|l|}{ Model 1} & \multicolumn{2}{|l|}{ Model 2} & \multicolumn{2}{|l|}{ Model 3} \\
\hline & $\beta(95 \% \mathrm{CI})$ & p-value & $\beta(95 \%$ CI $)$ & p-value & $\beta(95 \% \mathrm{CI})$ & p-value \\
\hline PCA SES Component 1 (z-score) & $-1.31(-1.80,-0.81)$ & $<0.001$ & $-1.49(-2.06,-0.92)$ & $<0.001$ & $-1.48(-2.11,-0.84)$ & $<0.001$ \\
\hline \multicolumn{7}{|c|}{ PCA SES Component 2 (linear splines) } \\
\hline Spline $1(\mathrm{z}$-score $<-1)$ & $-0.74(-4.77,3.28)$ & 0.718 & $-0.04(-3.89,3.81)$ & 0.984 & $0.10(-4.01,3.82)$ & 0.962 \\
\hline Spline 2 (z-score -1 to 0$)$ & $1.45(-1.87,4.77)$ & 0.393 & $0.98(-2.57,4.53)$ & 0.588 & $1.06(-2.41,4.52)$ & 0.550 \\
\hline Spline 3 (z-score $>0$ to 1$)$ & $-0.65(-3.28,1.97)$ & 0.627 & $-0.68(-3.48,2.11)$ & 0.631 & $-0.39(-3.25,2.48)$ & 0.790 \\
\hline Spline 4 (z-score $>1)$ & $0.76(-0.06,1.57)$ & 0.069 & $0.94(0.04,1.84)$ & 0.042 & $0.76(-0.21,1.73)$ & 0.127 \\
\hline \multicolumn{7}{|l|}{ FEMALES } \\
\hline PCA SES Component 1 (z-score) & $-0.46(-1.58,0.66)$ & 0.423 & $-0.51(-1.64,0.63)$ & 0.382 & $-0.48(-1.62,0.66)$ & 0.410 \\
\hline \multicolumn{7}{|c|}{ PCA SES Component 2 (linear splines) } \\
\hline Spline $1(\mathrm{z}$-score $<-1)$ & $-0.52(-2.83,1.80)$ & 0.662 & $-0.33(-2.63,21.97)$ & 0.778 & $-0.43(-2.74,1.89)$ & 0.719 \\
\hline Spline 2 (z-score -1 to 0$)$ & $4.02(1.71,6.33)$ & 0.001 & $3.97(1.36,6.57)$ & 0.003 & $4.09(1.49,6.69)$ & 0.002 \\
\hline Spline 3 (z-score 0 to 1$)$ & $-2.52(-4.82,-0.22)$ & 0.032 & $-2.84(-5.02,-065)$ & 0.011 & $-2.81(-5.04,-0.59)$ & 0.013 \\
\hline Spline 4 (z-score $>1)$ & $0.36(-1.16,1.88)$ & 0.645 & $0.60(-1.06,2.27)$ & 0.478 & $0.63(-1.05,2.31)$ & 0.463 \\
\hline
\end{tabular}

PCA = Principal Components Analysis; SES = socioeconomic status

Model 1: adjusted for age, household SES, and study

Model 2: adjusted for age, household SES, study, and BMI z-score

Model 3: adjusted for age, household SES, study, BMI z-score, glucose, physical activity, and fast food consumption

Coefficients for all variables in model three are shown in Table S13 of the supplementary tables file.

P-values from three level linear mixed effect models in Stata. Level 1 - individual study participants; level 2 - communities in which participant lived; level 3 - parish in which community was situated. Models used multiple imputation to account for missing data and used robust standard errors. 


\section{Table 6(on next page)}

Multivariable models for association between diastolic blood pressure and neighbourhood socioeconomic status for male and female participants 
Table 6: Multivariable models for association between diastolic blood pressure and neighbourhood socioeconomic status for male and female participants

\begin{tabular}{|c|c|c|c|c|c|c|}
\hline \multirow{2}{*}{$\begin{array}{l}\text { Characteristics } \\
\text { MALES }\end{array}$} & \multicolumn{2}{|l|}{ Model 1} & \multicolumn{2}{|l|}{ Model 2} & \multicolumn{2}{|l|}{ Model 3} \\
\hline & $\beta(95 \%$ CI $)$ & p-value & $\beta(95 \%$ CI) & p-value & $\beta(95 \%$ CI $)$ & p-value \\
\hline PCA SES Component 1 (z-score) & $-0.09(-0.76,0.58)$ & 0.794 & $-0.12(-0.79,0.56)$ & 0.735 & $-0.13(-0.84,0.59)$ & 0.730 \\
\hline \multicolumn{7}{|c|}{ PCA SES Component 2 (linear splines) } \\
\hline Spline $1(\mathrm{z}$-score $<-1)$ & $-4.28(-6.10,-2.47)$ & $<0.001$ & $-4.16(-5.99,-2.32)$ & $<0.001$ & $-4.10(-6.11,-2.09)$ & $<0.001$ \\
\hline Spline 2 (z-score -1 to 0 ) & $2.80(0.86,4.75)$ & 0.005 & $2.730 .80,4.66)$ & 0.006 & $2.85(1.05,4.66)$ & 0.002 \\
\hline Spline 3 (z-score $>0$ to 1$)$ & $-2.58(-4.71,-0.43)$ & 0.018 & $-2.59(-4.72,-0.46)$ & 0.017 & $-2.36(-4.88,0.17)$ & 0.067 \\
\hline Spline 4 (z-score >1) & $0.76(0.02,1.50)$ & 0.045 & $0.79(0.06,1.52)$ & 0.033 & $0.60(-0.25,1.44)$ & 0.167 \\
\hline \multicolumn{7}{|l|}{ FEMALES } \\
\hline PCA SES Component 1 (z-score) & $0.50(-0.68,1.68)$ & 0.406 & $0.48(-0.69,1.65)$ & 0.421 & $0.50(-0.65,1.65)$ & 0.395 \\
\hline \multicolumn{7}{|c|}{ PCA SES Component 2 (linear splines) } \\
\hline Spline $1(\mathrm{z}$-score $<-1)$ & $1.11(0.22,2.0)$ & 0.014 & $1.18(0.28,2.08)$ & 0.010 & $1.06(0.15,1.98)$ & 0.023 \\
\hline Spline 2 (z-score -1 to 0 ) & $0.19(-1.68,2.07)$ & 0.843 & $0.17(-1.66,2.01)$ & 0.854 & $0.27(-1.58,2.11)$ & 0.777 \\
\hline Spline 3 (z-score 0 to 1$)$ & $-1.47(-3.79,0.85$ & 0.215 & $-1.61(-3.82,0.59)$ & 0.153 & $-1.49(-3.73,0.76)$ & 0.194 \\
\hline Spline 4 (z-score >1) & $0.39(-0.69,1.47)$ & 0.480 & $0.49(-0.56,1.54)$ & 0.358 & $0.46(-0.61,1.54)$ & 0.397 \\
\hline
\end{tabular}

PCA = Principal Components Analysis; SES = socioeconomic status

Model 1: adjusted for age, household SES, and study

Model 2: adjusted for age, household SES, study, and BMI z-score

Model 3: adjusted for age, household SES, study, BMI z-score, glucose, physical activity, and fast food consumption

Coefficients for all variables in model three are shown in Table S14 of the supplementary tables file.

P-values from three level linear mixed effect models in Stata. Level 1 - individual study participants; level 2 - communities in which participant lived; level 3 - parish in which community was situated. Models used multiple imputation to account for missing data and used robust standard errors. 


\section{Table 7 (on next page)}

Multivariable model for association between elevated blood pressure or hypertension and covariates for male and female participants 
Table 7: Multivariable model for association between elevated blood pressure or hypertension and covariates for male and female participants

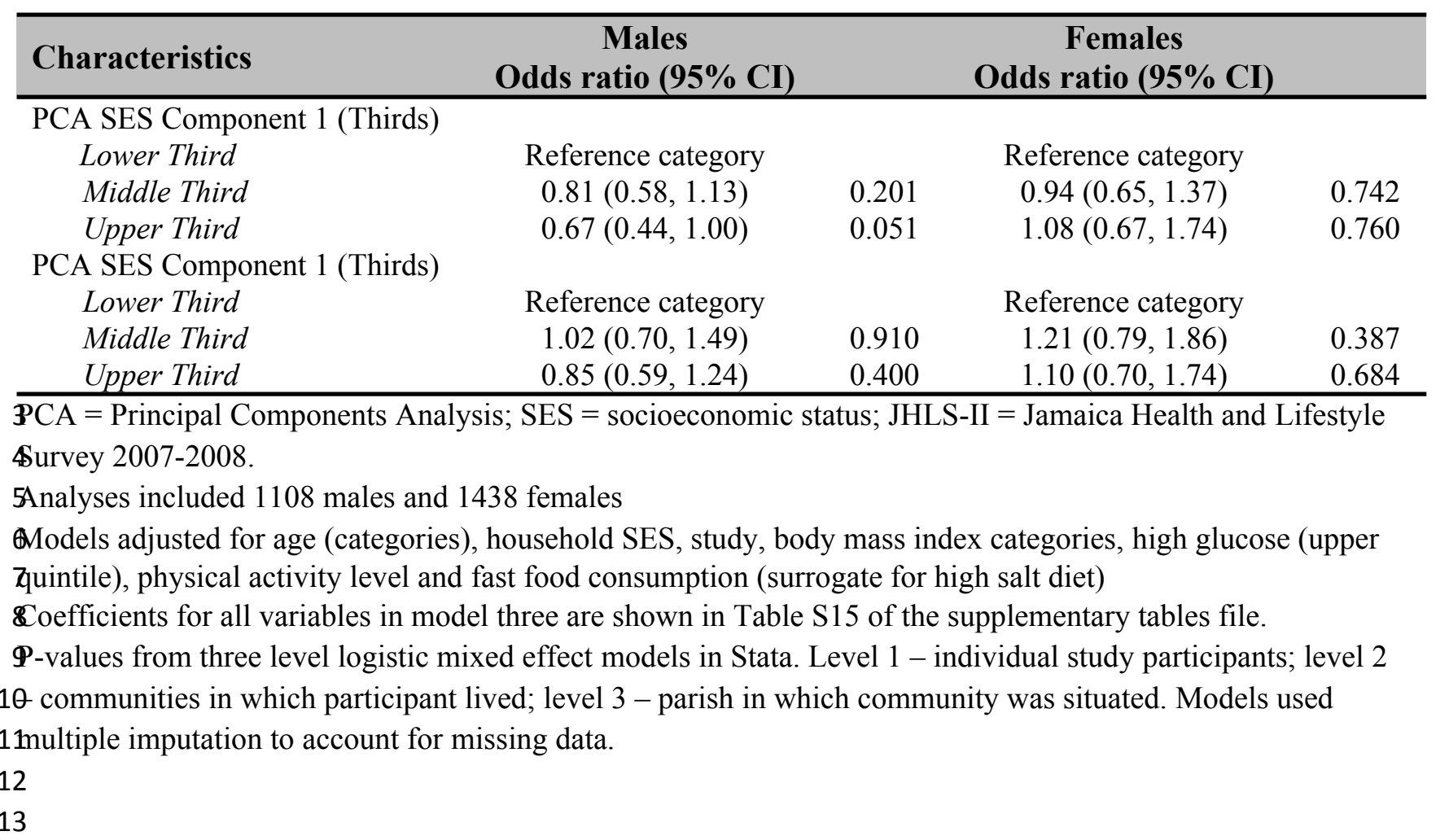

